\title{
Measuring Offence-Specific Forgiveness in Marriage: The Marital Offence-Specific Forgiveness Scale (MOFS)
}

\author{
F. Giorgia Paleari \\ University of Bergamo
}

\author{
Camillo Regalia \\ Catholic University of Milan
}

\author{
Frank D. Fincham \\ Florida State University
}

\begin{abstract}
Three studies involving 328 married couples were conducted to validate the Marital Offence-Specific Forgiveness Scale, a new measure assessing offence-specific forgiveness for marital transgressions. The studies examined the dimensionality; internal consistency; and discriminant, concurrent, and predictive validity of the new measure. The final scale comprised 2 distinct correlated dimensions, 1 positive (Benevolence) and 1 negative (Resentment-Avoidance), both of which had adequate internal consistency. The 2 dimensions discriminated marital forgiveness from affective empathy, rumination, attributions, and marital quality. Convergent validity of the new scale was indicated by significant relationships between its underlying dimensions and a host of predicted sociocognitive, relationship, trait, and well-being correlates of forgiveness. Providing evidence for predictive validity, forgiveness dimensions accounted for variability in relationship variables over a 6-month period.
\end{abstract}

Keywords: forgiveness, marriage, scale development, psychometrics, validity

The exponential growth of research on forgiveness reflects, in part, its presumed beneficial effects on relationship well-being, an idea reinforced by the fact that spouses themselves rate the seeking and granting of forgiveness as important for marital longevity and marital satisfaction (Fenell, 1993). Available research is consistent with this view in that forgiving the spouse enhances relationship intimacy and commitment, promotes effective conflict resolution, and has a positive influence on marital quality over time (Fincham \& Beach, 2007; Fincham, Beach, \& Davila, 2007; Paleari, Regalia, $\&$ Fincham, 2005; Tsang, McCullough, \& Fincham, 2006). In view of these beneficial effects, considerable effort has been devoted to identifying factors that may facilitate forgiveness in couple relationships. Among the more frequently investigated factors, the victim's sociocognitive reactions to the offence and the relational climate in which the offence takes place have consistently been shown to affect forgiveness toward the spouse (Fincham, Hall, \& Beach, 2005).

Notwithstanding progress in the study of marital forgiveness, there is need for the development of a psychometrically robust measure of forgiveness in couple relationships that might provide the platform for a more cumulative, integrated body of research in this domain. We attempt to address this need in the current article

F. Giorgia Paleari, Department of Human Language, Communication and Cultural Studies, University of Bergamo, Bergamo, Italy; Camillo Regalia, Athenaeum Center for Family Studies and Research, Catholic University of Milan, Milan, Italy; Frank D. Fincham, Family Institute, Florida State University.

Correspondence concerning this article should be addressed to F. Giorgia Paleari, Department of Human Language, Communication and Cultural Studies, University of Bergamo, Piazza Sant'Agostino 2 (Room 8), 24129 Bergamo, Italy. E-mail: francesca-giorgia.paleari@unibg.it and present psychometric data on the development of an offencespecific marital forgiveness scale. We first define offence-specific forgiveness as a multidimensional motivational construct and review measures commonly used in published research to assess it. Then we report the results of three studies in which we validated the Marital Offence-Specific Forgiveness Scale.

\section{Conceptualizing Offence-Specific Forgiveness}

Forgiveness can be defined and assessed at three different levels of specificity: as a trait, as a tendency toward a specific relationship partner, and as an offence-specific response (see McCullough, Hoyt, \& Rachal, 2000). Trait forgiveness, or forgivingness (Roberts, 1995), is the global disposition to forgive across multiple offences occurring in a variety of relationships and interpersonal situations; the tendency to forgive a relationship partner, or dyadic forgiveness (Fincham, Hall, \& Beach, 2005), is conceptualized as the proneness to forgive him/her across multiple offences; offencespecific forgiveness is defined as a single act of forgiveness for a specific offence within a particular interpersonal context. Existing research shows modest associations between offence-specific, dyadic, and trait forgiveness (e.g., Allemand, Amberg, Zimprich, \& Fincham, 2007; Eaton, Struthers, \& Santelli, 2006) as well as modest stability of forgiveness across multiple transgressions, even when they occur within a relatively short time period and within the same relationship context (e.g., McCullough \& Hoyt, 2002; Paleari et al., 2005). Thus, it seems that people take the specificity of an offense into account before forgiving or not forgiving it (e.g., its severity, intentionality, the degree to which it violates personal or relational standards).

Offence-specific forgiveness can be more narrowly conceptualized as a motivational change whereby one becomes less moti- 
vated to exact revenge or withdraw from the offending partner and more motivated to be benevolent and conciliatory toward him/her (Fincham, Hall, \& Beach, 2006; McCullough, 2001). Accordingly, offence-specific forgiveness is assumed to be multidimensional in that it implies at least two underlying dimensions: one positive and one negative. The positive dimension, sometimes called "benevolence," reflects the presence of benevolent and conciliatory motivation vis-à-vis the offender, or the desire to act with goodwill toward him/her. The negative dimension—called variously "unforgiveness," "avoidance," "revenge," or "retaliation"-involves the presence of vengeful and/or avoidant motivation. Although some authors assume that revenge motivations and avoidant motivations are in turn distinct dimensions (McCullough et al., 1998; McCullough, Worthington, \& Rachal, 1997), others suppose that they are indistinguishable in the close relationship context (Rye et al., 2001; Worthington \& Wade, 1999). In such relationships the desire to even the score and the desire to maintain a significant physical and psychological distance from the offending partner can often coexist.

Positive intent cannot be inferred from the absence of negative intent, just as health cannot be inferred from the absence of illness, and hence both dimensions are thought to be necessary in order to properly define and assess forgiveness in close relationships (Fincham, in press). Consistent with this view, data have been reported to show that the positive and negative dimensions of forgiveness have different correlates (Fincham \& Beach, 2002; Fincham et al., 2007).

\section{Measuring Offence-Specific Marital Forgiveness}

Although forgiveness has sometimes been assessed with singleitem self-reported measures (e.g., Afifi, Falato, \& Weiner, 2001; Karremans, Van Lange, Ouwerkerk, \& Kluwer, 2003), two multiitem scales have been developed specifically to assess different dimensions of offence-specific marital forgiveness: the Marital Forgiveness Scale (Fincham, Beach, \& Davila, 2004) and the Forgiveness Inventory (Gordon \& Baucom, 2003).

The Marital Forgiveness Scale is a nine-item measure focusing on the incident when the respondent felt most wronged or hurt by the partner. It yields three distinct but correlated subscales, of which two (Avoidance and Retaliation) reflect the negative dimension of forgiveness and one (Benevolence) reflects the positive dimension. Thus it is assumed that even though a spouse has not completely overcome his or her avoidant and/or revengeful intentions, he or she may at the same time be inclined to more benevolent ones.

In contrast, the Forgiveness Inventory consists of 23 items yielding three factors (Stage I, Stage II, and Stage III) that represent distinct temporal stages of the forgiveness process. These mirror a three-stage model of forgiveness according to which forgiveness parallels the three phases of recovery from traumatic events, that is, (a) impact, (b) search for meaning, and (c) recovery (e.g., Horowitz, 1985; Resick \& Calhoun, 2001). Thus, the Forgiveness Inventory is designed to assess stages of the forgiveness process rather than the extent to which the subject has forgiven the partner. In doing so, however, it evaluates processes such as attributions and accounts, which are more commonly viewed as distinct constructs affecting the forgiveness process rather than as features of it. Moreover, while some psychometric properties of the Forgiveness Inventory have been investigated, others, such as its predictive validity, have yet to be documented.
Although not specifically developed to assess marital forgiveness, some offence-specific measures of forgiveness have been used in marital research. One example is the 60-item Enright Forgiveness Inventory (Subkoviak et al., 1995; see use by Orathinkal \& Vansteenwegen, 2007). Besides being relatively long, the dimensionality of the scale, as far as we know, has never been demonstrated in samples of romantic partners.

Two other generic offence-specific measures have been used in marital research: the Forgiveness Scale (Rye et al., 2001) and the Transgression-Related Motivation Inventory (TRIM-12; McCullough et al., 1998). Both were more carefully analyzed psychometrically than were the Marital Forgiveness Scale, the Forgiveness Inventory, and the Enright Forgiveness Inventory previously reviewed. The Forgiveness Scale consists of 15 items designed to assess both positive and negative affective, cognitive, and behavioral responses to wrongdoing by any transgressor. As they were not intended to specifically measure responses to wrongdoing in close relationships, some Forgiveness Scale items are manifestly inappropriate for doing so (e.g., Item 7: "If I encountered the person who wronged me I would feel at peace," and Item 5: "I avoid certain people and/or places because they remind me of the person who wronged me").

The TRIM-12 is a generic measure that was designed to accommodate measurement of forgiveness in close relationships. It consists of 12 items that assess revenge and avoidant motivations toward the offender. It was made to conform to more recent conceptualizations of forgiveness with the addition of six more items assessing benevolent and conciliatory motivations (TRIM-18; see McCullough, Root, \& Cohen, 2006). The TRIM-18, however, has never been validated, and its dimensional structure seems unstable across samples. For example, while some studies have found that its three subscales are highly intercorrelated, suggesting one underlying dimension (Exline, Baumeister, Bushman, Campbell, \& Finkel, 2004; Hoyt, Fincham, McCullough, Maio, \& Davila, 2005), others have found three distinct dimensions (Fincham et al., 2004) or two distinct dimensions (Benevolence and Avoidance loaded on one dimension and Revenge loaded on the other one; McCullough et al., 2006). Moreover, like the Enright Forgiveness Inventory and the Forgiveness Scale previously reviewed, the psychometric properties of the TRIM-18 have never been investigated in marriage. This is disappointing because some TRIM items appear to be too harsh to assess adequately lack of forgiveness between partners involved in an ongoing relationship. In particular, they describe reactions, like the motivation to cut off the relationship and to see the partner hurt and miserable, which are likely to happen only in response to extremely serious and hurtful offences (e.g., infidelity), rather than to everyday offences (e.g., unfair criticism) found in marital relationships.

Given that existing offence-specific measures have questionable criterion-related and content validity for marital forgiveness research, we developed and evaluated a new measure, the Marital Offence-Specific Forgiveness Scale (MOFS), which was designed to address these limitations. Consistent with other existing scales (the Marital Forgiveness Scale and the TRIM-18), the MOFS assesses forgiveness through the presence of benevolent motivations and the absence of avoidant, resentful, or revengeful ones.

\section{Study 1}

Study 1 investigated the dimensionality of the MOFS with a sample of long-term married couples. Due to the nonindependence 
of couple data (Kenny, 1996), we examined three competing models separately for husbands and wives: (a) a three-factor oblique model comprising Avoidance, Revenge-Resentment, and Benevolence (McCullough et al., 1998; 1997); (b) a two-factor oblique model comprising Unforgiveness (including Avoidance and Revenge-Resentment items) and Benevolence (Fincham et al., 2006; Rye et al., 2001; Worthington \& Wade, 1999); and (c) a single-factor model that hypothesized that all the forgiveness items were the expression of one latent factor, as found in some previous studies (Exline et al., 2004; Hoyt et al., 2005). Equality of husbands' and wives' solutions was then evaluated by reestimating them simultaneously in a single model and placing constraints on corresponding paths for each spouse (see Kenny, Kashy, \& Cook, 2006).

Study 1 also provides initial evidence on discriminant and convergent validity. Discriminant validity was tested by determining whether the MOFS items were empirically distinct from items assessing conceptually related but distinct constructs. The most proximal predictors of offence-specific forgiveness have been theoretically assumed and empirically shown to be the affective and cognitive processes victims develop in response to an offence (e.g., Fincham, Paleari, \& Regalia, 2002; McCullough et al., 1998; Paleari et al., 2005). Specifically, ruminative thoughts and unfavorable attributions regarding offender behavior are positively related to victims' avoidance and revenge motivations and are negatively related to victims' benevolent motivations. Affective empathy for the transgressor is also related to forgiveness dimensions but in the opposite manner (e.g., McCullough, Bono, \& Root, 2007). In light of this evidence, it is important to show that the MOFS provides unique information over and beyond that provided by items assessing related affective-cognitive processes caused by the offence. Also, marital offence-specific forgiveness is strongly associated with the relational climate, with more forgiving and less avoidant and vengeful partners being involved in more intimate and satisfying romantic relationships (for a review, see Fincham, Hall, \& Beach, 2005). Thus, it is important to show that the MOFS is not a proxy index of marital quality. Such evidence would disconfirm the sentiment override hypothesis according to which spouses simply respond to research questions about marital forgiveness in terms of their dominant feeling or sentiment about the relationship (Fincham, Garnier, Gano-Phillips, \& Osborne, 1995).

Convergent validity was investigated by examining correlations between the MOFS and a host of scales assessing theoretically related constructs. We evaluated, besides the victims' affectivecognitive processes and marital quality, associations with measures of several logically related constructs. First, given that forgiveness is more easily granted when the transgression is perceived as less severe (e.g., Fincham, Jackson, \& Beach, 2005; Williamson \& Gonzales, 2007), we predicted that the MOFS would be negatively associated with the perceived hurtfulness and seriousness of the offence. Second, we investigated associations between the MOFS and marital quality, marital support, and closeness as rated by both the victim and his/her offending partner. Obtaining information from the partner about likely correlates of offence-specific forgiveness helps to rule out the possibility that associations observed in the data are simply due to same-source variance. We predicted that more forgiving and less avoidant and revengeful spouses would have more satisfying, close, and supportive marital relationships (see Fincham, Hall, \& Beach, 2005).
Finally, offence-specific forgiveness has been shown to correlate with several mental health indicators, including satisfaction with life and self-esteem, which are strengthened by forgiveness, and depression and stress, which are reduced by it (e.g., Karremans et al., 2003; Lawler et al., 2005; Reed \& Enright, 2006). We hypothesized that, on the basis of this evidence, the MOFS would be associated with the victim's levels of depression, self-esteem, stress, and satisfaction with life.

\section{Method}

\section{Participants and Procedure}

Participants were 148 couples married an average of 18.5 years $(S D=7.37)$ and living in Northern Italy. The mean ages of husbands and wives were $46.12(S D=7.26)$ and $43.56(S D=$ 6.97) years, respectively.

They were recruited by inviting students in secondary schools and in undergraduate courses to ask both their parents to participate in a study on marital relationships. Couples who volunteered to participate received two packets, one for the husband and one for the wife, containing a questionnaire, return envelopes, and a cover letter instructing them on their task. The importance of independent completion of the materials was emphasized in the letter, and the couple was asked to mail the questionnaires within 1 week and not to talk about the study until after they had mailed them.

\section{Measures}

Subjects were asked to recall in detail the most serious offence by their spouse during the last 6 months. They indicated offense seriousness and how hurtful the offense was, respectively, with 7-point Likert scales ranging from 1 (not serious at all) to 7 (very serious) and 1 (not hurtful at all) to 7 (very hurtful). On average husbands and wives remembered moderately serious and hurtful offences: hurtfulness: $M=3.84(S D=1.56)$ and $4.36(S D=1.67)$ for husbands and wives, respectively; seriousness: $M=3.18(S D=1.68)$ and $3.72(S D=$ 1.61) for husbands and wives, respectively.

MOFS. As a first step in developing the scale, we generated items to tap different facets of the construct of forgiveness. Relying upon a common conceptualization of the construct (see Fincham et al., 2006; McCullough, 2001), we adapted items from existing scales and developed new ones to assess the presence of benevolent and conciliatory motivations and the absence of vengeful or withdrawing ones toward the offending partner. We also developed-following Enright, Freedman, and Rique (1998), who depicted forgiveness as letting go of resentment - a number of items assessing the absence of resentful motivations. We assumed that unforgiving spouses hold grudges and lasting resentment against their partner even in contexts where they do not want to directly inflict any harm on him/her. In generating items, we carefully avoided overlap with related but distinct constructs (e.g., blame attributions, apology, and empathy). The set of items was progressively refined and reduced on the basis of pilot studies that tested the understandability and discriminative power of each item on a sample of 200 spouses.

The MOFS consisted of 12 items: 5 assessing benevolent motivations (e.g., "Although she/he hurt me, I definitely put what happened aside so that we could resume our relationship"), 5 
assessing resentful or revengeful motivations (e.g., "I still hold some grudge against my wife/husband because of what she/he did," "I would like to behave to my wife/husband the same way that she/he behaved toward me"), and 2 assessing avoidant motivations (e.g., "Since my wife/husband behaved that way, I have been less willing to talk to her/him"). Participants were then asked to rate on a 6-point scale ranging from 1 (strongly disagree) to 6 (strongly agree) their degree of forgiveness on the basis of the 12 items.

Responsibility attributions. Responsibility attributions were assessed with three items from the Relationship Attribution Measure (Fincham \& Bradbury, 1992). Spouses were asked to evaluate on a scale ranging from 1 (strongly disagree) to 6 (strongly agree) the extent to which they agreed with three statements assessing partner intent, motivation, and blame for the offence (e.g., "My husband/wife behaved that way on purpose"). Scores were averaged across items so that higher scores indicated greater responsibility for the offence. The coefficient alpha was .65 for husbands and .66 for wives.

Rumination. We measured rumination about intrusive thoughts, affects, and imagery related to the offense by having spouses complete the seven-item Intrusiveness subscale of the Impact of Event Scale (Horowitz, Wilner, \& Alvarez, 1979). They were asked to evaluate each item of the scale (e.g., "I thought about it when I didn't mean to") on a 4-point rating scale ranging from 1 (never) to 4 (often). One item originally on the scale ("I dreamed about the incident") was omitted because earlier studies (e.g., Paleari et al., 2005) carried out on an Italian sample showed that it yielded a strongly skewed distribution. The coefficient alpha was .86 for husbands and .84 for wives.

Emotional empathy. Emotional empathy toward the offending spouse was measured with a three-item scale previously employed in a study of forgiveness in families (Paleari et al., 2005) in which participants rated on a 7-point scale ranging from 1 (not at all) to 7 (very much) the extent to which they felt each of three emotions (sympathy, tolerance, indulgence) toward the offending partner. The coefficient alpha was .87 for husbands and .80 for wives.

Marital quality. Marital quality was measured with the Quality of Marriage Index (QMI; Norton, 1983). This six-item inventory assesses marital quality with broadly worded, global items (e.g., "We have a good marriage"). Respondents show their degree of agreement with each of five items on a 7-point Likert-type scale ranging from 1 (very strong disagreement) to 7 (very strong agreement) and with one item on a 10-point Likert-type scale ranging from 1 (very strong disagreement) to 10 (very strong agreement). Since the data were positively skewed, the following transformation recommended by Norton (1983) was used: $\mathrm{QMI}^{*}=.001\left(\sum \mathrm{zi}+\mathrm{v}\right)^{3}$ where $\mathrm{QMI}^{*}=$ transformed QMI, zi = standardized score, and $\mathrm{v}=$ variance across intervals obtained by stratifying the distribution of the QMI into 5\% intervals. The coefficient alpha was .95 for husbands and .96 for wives.

Closeness. Relational closeness was measured with the Inclusion of Other in the Self (IOS) Scale (Aron, Aron, \& Smollan, 1992). This single-item measure consists of seven Venn diagrams, each of which is composed of two circles marked Self and Other. The seven pictures portray progressively increasing degrees of overlap between the circles to symbolize varying degrees of closeness that someone might experience toward another person. In the present study, Other was replaced by My Husband or My Wife.
Aron et al. (1992) found that the IOS Scale had high test-retest reliabilities, had high correlations with other measures of relational closeness, and was sensitive to experimental manipulations designed to manipulate relational closeness.

Marital support. A 14-item support scale (Paleari, Rosnati, \& Lanz, 2002) was used to measure perceived marital support given and received within the marriage (e.g., "When I need it, my wife helps me," "When my wife needs it, I help my wife"). Spouses rated their degree of agreement with each item on a 5-point Likert-type scale ranging from 1 (very strong disagreement) to 5 (very strong agreement). Two items originally on the scale were omitted, as they yielded strongly skewed distributions. The coefficient alpha for the remaining 12 items, which loaded on a single factor, was .90 for husbands and .89 for wives.

Depression. The Center for Epidemiologic Studies Depression (CES-D) Scale was used to measure depression (Radloff, 1977). The scale consists of 20 items describing a variety of depressive symptoms (e.g., "I felt that I could not shake off the blues even with the help from my family or friends," "I felt that everything I did was an effort"). Participants reported on 4-point Likert-type scale ranging from 0 (Rarely or none of the time) to 3 (Most or all of the time) the frequency with which they had experienced each of the symptoms during the previous week. The coefficient alpha was .85 for husbands and .90 for wives.

Self-esteem. We assessed self-esteem with the Rosenberg SelfEsteem Scale (Rosenberg, 1965). The version used in this study contained six items (e.g., "I feel that I'm a person of worth, at least on an equal basis with others") rated on a 4-point Likert-type scale ranging from 1 (strongly disagree) to 4 (strongly agree). The coefficient alpha was .71 for husbands and .77 for wives.

Stress. Stress was measured with the what's your stress index? (WYSI) developed by the Canadian Mental Health Association (n.d.). The instrument is composed of 24 questions that assess current experiences of stress (e.g., "Do you frequently blow up easily?" "Do you frequently get too little rest?"). The answers to these questions are given in a yes-no format; consequently, the Kuder-Richardson formula (K-R 20) was used to compute the internal consistency reliability ( $\alpha=.70$ for husbands and .71 for wives).

Satisfaction with life. Participants reported their overall satisfaction with life on the Satisfaction With Life Scale (SWLS; Diener, Emmons, Larsen, \& Griffin, 1985). They rated their agreement with the five items on a scale ranging from 1 (strongly disagree) to 7 (strongly agree). The SWLS measures the cognitive component of subjective well-being (e.g., "In most ways my life is close to ideal"). In previous studies the scale was negatively correlated with measures of psychological distress and neuroticism and positively correlated with extraversion. The coefficient alpha was .86 for husbands and .88 for wives.

Assessment in this and in the two subsequent studies reported in this article was conducted in Italian. English measures that had never been used and validated in Italy ${ }^{1}$ were translated into Italian by means of a back-translation procedure, following guidelines of the International Test Commission (Hambleton, 1994). Specifically, a bilingual psychologist translated each measure from En-

\footnotetext{
${ }^{1}$ English measures that, as far as we know, were translated into Italian for the first time were the Stress Index Test in Study 1, as well as the Ineffective Arguing Inventory and the Trait Forgivingness Scale in Study 3.
} 
glish to Italian and subsequently an independent bilingual psychologist translated it back to English. Differences were discussed until a consensus translation was obtained. The translated instruments were next checked for preservation of meaning and cultural appropriateness. Finally, pilot testing was undertaken to ensure that the instruments were comprehensible. The same back-translation procedure was followed when translating new forgiveness items from Italian to English.

\section{Data Analytic Strategy}

In all three studies, confirmatory factor analyses (CFA) and SEM models were estimated with EQS 6 (Bentler, 2005). Mardia's (1970) coefficients suggested significant deviations from multivariate normality for all CFA models. To reduce the impact of nonnormality we therefore relied on Satorra and Bentler (2001) scaled estimates in rescaling the standard errors and the chi-square statistics into the Satorra-Bentler scaled chi-square $\left(\mathrm{S}-\mathrm{B} \chi^{2}\right)$ statistic. Fit indexes like the comparative fit index (CFI; Bentler, 1990) and the root-mean-square error of approximation (RMSEA; Bentler, 1995) were also adjusted for nonnormality by incorporating the $\mathrm{S}-\mathrm{B} \chi^{2}$ into their calculations. We refer to them as robust estimates (i.e., R-CFI, R-RMSEA).

To evaluate goodness of fit, we examined the $\mathrm{S}-\mathrm{B} \chi^{2}$, the R-CFI, the R-RMSEA, and its $90 \%$ confidence interval (CI). A significant chi-square statistic may indicate that the hypothesized model does not fit the observed data. However, because the chi-square statistic is oversensitive to sample size, alternative fit indexes like the R-CFI and R-RMSEA are generally used. An R-CFI of .90 or greater and R-RMSEA values of .08 or lower with the high end of the $\mathrm{CI}$ not exceeding 0.10 are considered an adequate fit, whereas an R-CFI in the mid .90s and R-RMSEA values of .05 or lower with the high end of the CI not exceeding .08 indicate a good fit (Kline, 2005; Raykov \& Marcoulides, 2000; Ullman, 2001).

Also, since in the present study some subjects had missing data on a few empathy, rumination, or attributions items, fit statistics of CFAs distinguishing forgiveness dimensions from affectivecognitive variables were adjusted through use of the robust maximum likelihood estimation (MLE) with the expectationmaximization algorithm (Jamshidian \& Bentler, 1999) and the Yuan-Bentler scaled chi-square (Y-B $\chi^{2}$; Yuan \& Bentler, 1998). The $\mathrm{Y}-\mathrm{B} \chi^{2}$ is analogous to the $\mathrm{S}-\mathrm{B} \chi^{2}$, except that it represents a technical advancement by allowing for missing data. MLE has been shown to be less biased and more efficient than are other missing data procedure methods, such as listwise or pairwise deletion (Wothke, 2000).

\section{Results and Discussion}

\section{Dimensionality}

First, we conducted exploratory factor analysis on husbands' data and, consistent with Russell's (2002) recommendations, extracted factors with principal axis factoring and an Oblimin rotation. The number of factors extracted was determined through examination of the scree plot, eigenvalues larger than 1.0, and residuals between observed and reproduced correlations smaller than I.10 | (McDonald, 1985). Examination of factor loadings led to the removal of one positive item that loaded less than $|.30|$ and one negative item with high cross loadings. The exploratory factor analyses on the remaining 10 items revealed two correlated factors that explained $58.9 \%$ of the total item variance. The two Avoidance items and the four Revenge-Resentment items loaded strongly and positively on the first factor, explaining $35.5 \%$ of husbands' total item variance. The four Benevolence items loaded strongly and positively on the second factor, explaining $23.4 \%$ of husbands' total item variance. We named the first factor Resentment-Avoidance and the second one Benevolence.

Second, using wives' data we assessed the validity of the twofactor solution for the 10 retained items by means of CFA. The two-factor oblique model, in which the six Resentment-Avoidance items were allowed to load on one factor and the four Benevolence items on another related factor, provided a good fit to wives' data, $\mathrm{S}-\mathrm{B} \chi^{2}(32)=34.56, p=.35, \mathrm{R}-\mathrm{CFI}=.99, \mathrm{R}-\mathrm{RMSEA}=.02$ (90\% CI $=0.00-0.07)$. The two factors were correlated at $r=$ -.63 , and all factor loadings were greater than .40 .

Third, we tested whether a single latent variable model accounted for the observed covariance among the 10 items. The one-factor model was then compared with the two-factor model by means of a model comparison procedure introduced by Bollen (1980). By comparing the hypothesized two-factor model with a model where the association between the two dimensions of forgiveness is constrained to be one (thereby positing a single factor), two- and one-factor models can be evaluated by interpreting the change in chi-square (per change in $d f$ ) as a chi-square statistic. Mirroring results from exploratory factor analysis, the two-factor model provided a good fit to husbands' data as well, S-B $\chi^{2}(32)=$ 43.76, $p=.08$, R-CFI $=.97$, R-RMSEA $=.05(90 \% \mathrm{CI}=$ $0.00-0.08$ ); correlation between factors $=-.69$. However, when the association between Resentment-Avoidance and Benevolence dimensions was constrained to unity, there was a poor fit to the husbands' and wives' data: husbands: $\mathrm{S}-\mathrm{B} \chi^{2}(33)=87.99, p=$ $.00, \mathrm{R}-\mathrm{CFI}=.85, \mathrm{R}-\mathrm{RMSEA}=.11(90 \% \mathrm{CI}=0.08-0.13)$; wives: $\mathrm{S}-\mathrm{B} \chi^{2}(33)=83.35, p=.00, \mathrm{R}-\mathrm{CFI}=.85, \mathrm{R}-\mathrm{RMSEA}=$ $.10(90 \% \mathrm{CI}=0.07-0.13)$, and a significant change in chi-square for both husbands and wives: husbands: $\Delta \chi^{2}(1)=44.23, p<.001$; wives: $\Delta \chi^{2}(1)=48.79, p<.001$. Accordingly, the two-factor solution is preferable to a single-factor solution.

Fourth, we examined whether a three-factor oblique model-in which the two Avoidance items, the four Revenge-Resentment items, and the four Benevolence items were allowed to load on three distinct correlated factors-reproduced the covariance among the items. The three-factor solution provided a good fit to the data: husbands: $\mathrm{S}-\mathrm{B} \chi^{2}(30)=42.98, p=.06, \mathrm{R}-\mathrm{CFI}=.98$, $\mathrm{R}-\mathrm{RMSEA}=.05(90 \% \mathrm{CI}=0.00-0.09)$; wives: $\mathrm{S}-\mathrm{B} \chi^{2}(30)=$ $30.46, p=.44$, R-CFI $=1.00$, R-RMSEA $=.00(90 \% \mathrm{CI}=$ 0.00-0.05). However, when the association between Avoidance and Revenge-Resentment dimensions was constrained to unity, there was an equally good fit to the data: husbands: $\mathrm{S}-\mathrm{B} \chi^{2}(31)=$ 43.14, $p=.07$, R-CFI $=.97$, R-RMSEA $=.05(90 \% \mathrm{CI}=$ $0.00-0.09), \Delta \chi^{2}(1)=0.16, p=n s$; wives: $\mathrm{S}-\mathrm{B} \chi^{2}(31)=33.73$, $p=.34, \mathrm{R}-\mathrm{CFI}=.99, \mathrm{R}-\mathrm{RMSEA}=.02(90 \% \mathrm{CI}=0.00-0.07)$, $\Delta \chi^{2}(1)=3.27, p=n s$. Thus, because of its parsimony, a model comprising two correlated latent variables of ResentmentAvoidance and Benevolence appeared most appropriate.

Finally, following Kenny et al.'s (2006) recommendations, we tested the congruence of the two-factor solution across gender by estimating husbands' and wives' factor solutions simultaneously in 
a single model and placing constraints on corresponding loadings. Specifically, factor loadings on each dimension were set to be equal for the two members of the couple so as to test congruence; additionally latent factors as well as errors across the same indicators were allowed to correlate across husbands and wives, reflecting nonindependence across the two members of the couple. The model fit was good, $\mathrm{S}-\mathrm{B} \chi^{2}(160)=192.17, p=.04$, R-CFI $=$ $.97, \mathrm{R}-\mathrm{RMSEA}=.04(90 \% \mathrm{CI}=0.01-0.06)$, indicating that the Resentment-Avoidance and Benevolence dimensions have the same meaning for both husbands and wives. ${ }^{2}$

The internal consistency reliability was good for both the Resentment-Avoidance dimension $(\alpha \mathrm{s}=.83$ for husbands and .79 for wives) and the Benevolence dimension ( $\alpha \mathrm{s}=.80$ for husbands and .75 for wives). The final version of the MOFS appears in the Appendix.

\section{Discriminant Validity}

The discriminant validity of the MOFS was examined by means of CFA. CFA is commonly considered a more stringent test than are correlation methods because it evaluates discriminant validity by taking into account differential reliability of measurements and by drawing conclusions on the basis of fit indexes rather than on a set of rules of thumb (Bagozzi, Yi, \& Phillips, 1991; Kenny \& Kashy, 1992). To provide evidence of discriminant validity, we distinguished each of the MOFS dimensions (i.e., ResentmentAvoidance and Benevolence) from measures of emotional empathy, rumination, attributions, and marital quality. If the MOFS dimensions are distinct from each of these measures, two distinct correlated factors should account for the covariances among the items. To test this hypothesis we first estimated a series of twofactor solutions specifying that the items on each of the MOFS dimensions and on each of the other relevant scales loaded on two distinct but correlated latent variables. We then compared these two-factor solutions with a series of one-factor solutions by specifying a single latent variable underlying the items on each of the MOFS dimensions and on each of the other relevant scales. Being nested models, the two- and the one-factor solutions were evaluated by interpreting the change in chi-square (per change in $d f$ ) as a chi-square statistic. If the two-factor oblique solutions were superior to the corresponding one-factor solutions, we could conclude that the MOFS dimensions are distinct from scales measuring related constructs.

The model fit for the two- and the one-factor solutions, as well as the change in chi-square, are reported in Table 1. The two-factor solutions, distinguishing the Resentment-Avoidance or the Benevolence factor from the related construct (i.e., empathy, rumination, attributions, or marital quality) were always preferable to the one-factor solutions. Also, the two-factor solutions exhibited satisfactory fit except for the models correlating wives' Benevolence with their marital quality. This indicated that the MOFS dimensions assess a construct that is related to, but not equivalent to, the one assessed by offence-specific empathy, rumination, and attributions scales. The MOFS also showed some discriminant validity with regard to marital quality.

\section{Convergent Validity}

We next proceeded to evaluate the convergent validity of the MOFS by examining the correlations of its Resentment-
Avoidance and Benevolence dimensions with offence-specific affective-cognitive processes, perceived offence severity, relationship variables, and indicators of well-being (see Table 2).

Affective-cognitive reactions to the offence. As predicted, MOFS dimensions were correlated in the expected direction, for both husbands and wives, with responsibility attributions, ruminative thoughts, and emotional empathy. Replicating previous findings (Hall \& Fincham, 2006; McCullough et al., 2007, 1998; Paleari et al., 2005), the results revealed that the more the spouses ruminated about the offence, attributed its responsibility to their partner, and were less empathetic toward him/her, the more they were resentful, avoidant, and not benevolent. Ruminative thoughts were more strongly related to Resentment-Avoidance than to Benevolence in both husbands $(p=.00$, test for significant difference between dependent correlations; Cohen \& Cohen, 1983) and wives $(p=.03)$. Also, responsibility attributions were more strongly related to Resentment-Avoidance than to Benevolence $(p=.00)$, whereas emotional empathy was more strongly associated with Benevolence than with Resentment-Avoidance ( $p=$ .00 ) in husbands only. These findings are consistent with previous research that shows rumination about an offence heightens readiness to avoid and/or seek revenge against a transgressor, while empathizing with him/her facilitates benevolent motivations (McCullough et al., 2007, 1998).

Offence severity. As predicted, MOFS dimensions were also correlated in the expected direction with the perceived hurtfulness and seriousness of the offence in both husbands and wives. Participants who perceived the offence as more hurtful and serious were, consistent with previous evidence (e.g., Williamson \& Gonzales, 2007), more resentful/avoidant and less benevolent toward their spouse.

Relationship variables. As predicted, MOFS dimensions covaried in the expected direction with the relationship variables studied in both husbands and wives. Spouses who were more benevolent and less resentful/avoidant in response to the offence had more satisfying, close, and supportive marital relationships than did their less forgiving counterparts. It is interesting that MOFS dimensions were significantly correlated to nearly all relationship variables when they were rated not only by the respondent but also by his/her partner. This suggests that the associations observed are not due to use of a single reporter.

Indicators of psychological well-being. As predicted, MOFS dimensions were significantly correlated, in both husbands and wives, with nearly all indicators of psychological well-being. Spouses who were more benevolent and less avoidant and resentful had higher levels of self-esteem, were less depressed and distressed, and were more satisfied with their life than were less forgiving spouses. These results are consistent with previous evidence showing that forgiveness covaries with psychological wellbeing (e.g., Karremans et al., 2003; Rye et al., 2001).

\footnotetext{
${ }^{2}$ Because the ratio of parameters estimated to subjects was 2.5 , that is, lower than the 5 recommended by some authors (e.g., Bentler \& Chou, 1987), we tested the same model with Study 1 and Study 3 samples combined, yielding a parameters estimated to subjects ratio of 5.5. The model showed a good fit to the data in this larger sample as well, $\mathrm{S}-\mathrm{B} \chi^{2}(160)=240.39, p=.00, \mathrm{R}-\mathrm{CFI}=.96, \mathrm{R}-\mathrm{RMSEA}=.04(90 \% \mathrm{CI}=$ $.03-.05)$.
} 
Table 1

Factor Solutions Examining the Discriminant Validity of the MOFS Dimensions in Relation to Empathy, Rumination, Attributions, and Marital Quality (Study 1)

\begin{tabular}{|c|c|c|c|c|c|c|c|c|c|c|c|c|}
\hline \multirow[b]{2}{*}{$\begin{array}{l}\text { MOFS dimension and } \\
\text { scale }\end{array}$} & \multicolumn{5}{|c|}{ Two-factor solutions } & \multicolumn{5}{|c|}{ One-factor solutions } & \multirow[b]{2}{*}{$\Delta \chi^{2}(1)$} & \multirow[b]{2}{*}{$p$} \\
\hline & $x^{2 a}$ & $d f$ & $p$ & R-CFI & $\begin{array}{l}\text { R-RMSEA } \\
(90 \% \mathrm{CI})\end{array}$ & $x^{2 \mathrm{a}}$ & $d f$ & $p$ & $\mathrm{R}-\mathrm{CFI}$ & $\begin{array}{l}\text { R-RMSEA } \\
(90 \% \mathrm{CI})\end{array}$ & & \\
\hline \multicolumn{13}{|c|}{ Husbands } \\
\hline \multicolumn{13}{|l|}{ Resentment-Avoidance } \\
\hline Empathy & 42.87 & 25 & .01 & .97 & $.07(0.05-0.10)$ & 202.81 & 26 & .00 & .72 & $.22(0.19-0.24)$ & 159.94 & $<.001$ \\
\hline Rumination & 64.37 & 52 & .12 & .98 & $.04(0.00-0.07)$ & 150.72 & 53 & .00 & .82 & $.11(0.09-0.13)$ & 86.35 & $<.001$ \\
\hline Attributions & 43.74 & 25 & .01 & .96 & $.07(0.03-0.10)$ & 82.02 & 26 & .00 & .85 & $.12(0.09-0.15)$ & 38.28 & $<.001$ \\
\hline Marital quality & 94.36 & 52 & .00 & .91 & $.07(0.05-0.10)$ & 197.37 & 53 & .00 & .69 & $.14(0.12-0.16)$ & 103.01 & $<.001$ \\
\hline \multicolumn{13}{|l|}{ Benevolence } \\
\hline Empathy & 15.57 & 12 & .21 & 1.00 & $.05(0.00-0.10)$ & 79.67 & 13 & .00 & .84 & $.19(0.15-0.23)$ & 64.00 & $<.001$ \\
\hline Rumination & 20.07 & 33 & .96 & 1.00 & $.00(0.00-0.02)$ & 127.83 & 34 & .00 & .80 & $.14(0.11-0.16)$ & 107.76 & $<.001$ \\
\hline Attributions & 12.89 & 12 & .38 & 1.00 & $.02(0.00-0.09)$ & 76.56 & 13 & .00 & .77 & $.18(0.14-0.22)$ & 63.67 & $<.001$ \\
\hline Marital quality & 35.83 & 33 & .34 & .99 & $.02(0.00-0.07)$ & 96.13 & 34 & .00 & .85 & $.11(0.09-0.14)$ & 60.30 & $<.001$ \\
\hline \multicolumn{13}{|c|}{ Wives } \\
\hline \multicolumn{13}{|l|}{ Resentment-Avoidance } \\
\hline Empathy & 26.07 & 25 & .40 & 1.00 & $.02(0.00-0.07)$ & 117.43 & 26 & .00 & .78 & $.16(0.13-0.18)$ & 91.36 & $<.001$ \\
\hline Rumination & 58.97 & 52 & .24 & .99 & $.03(0.00-0.06)$ & 142.00 & 53 & .00 & .82 & $.11(0.09-0.13)$ & 84.03 & $<.001$ \\
\hline Attributions & 26.31 & 25 & .39 & 1.00 & $.00(0.00-0.07)$ & 54.29 & 26 & .00 & .91 & $.09(0.05-0.12)$ & 27.98 & $<.001$ \\
\hline Marital quality & 99.13 & 52 & .00 & .95 & $.08(0.05-0.10)$ & 181.39 & 53 & .00 & .87 & $.13(0.11-0.15)$ & 82.26 & $<.001$ \\
\hline \multicolumn{13}{|l|}{ Benevolence } \\
\hline Empathy & 15.30 & 12 & .23 & .99 & $.04(0.00-0.10)$ & 110.63 & 13 & .00 & .71 & $.22(0.19-0.26)$ & 95.33 & $<.001$ \\
\hline Rumination & 40.66 & 33 & .17 & .98 & $.04(0.00-0.08)$ & 129.74 & 34 & .00 & .78 & $.14(0.11-0.16)$ & 89.08 & $<.001$ \\
\hline Attributions & 14.23 & 12 & .29 & 1.00 & $.04(0.00-0.09)$ & 51.90 & 13 & .00 & .84 & $.14(0.10-0.18)$ & 37.67 & $<.001$ \\
\hline Marital quality & 105.00 & 33 & .00 & .92 & $.12(0.10-0.15)$ & 175.58 & 34 & .00 & .85 & $.17(0.14-0.19)$ & 70.25 & $<.001$ \\
\hline
\end{tabular}

Note. $\quad N=148$. MOFS $=$ Marital Offence-Specific Forgiveness Scale; R-CFI $=$ robust estimate of comparative fit index; R-RMSEA $=$ robust estimate of root-mean-square error of approximation; CI = confidence interval.

${ }^{a}$ Confirmatory factor analyses (CFAs) examining the discriminant validity of the MOFS dimensions in relation to marital quality were evaluated through the Satorra-Bentler chi-square statistics, while the remaining CFAs were evaluated through the Yuan-Bentler chi-square statistics, which allow for missing data.

Overall, the moderate to strong correlations between the MOFS dimensions and the other constructs investigated provided evidence for the concurrent validity of the scale. Given that concurrent validity provides necessary but not sufficient evidence for the validity of an instrument, Study 2 documented the MOFS's ability to predict related constructs.

\section{Study 2}

Some longitudinal studies have demonstrated that forgiving the partner facilitates relational closeness and higher relationship quality following an interpersonal transgression (Fincham \& Beach, 2007; Paleari et al., 2005; Tsang et al., 2006). These long-term beneficial effects of forgiveness were more likely among spouses married to partners who infrequently engaged in negative behaviors, whereas forgiveness appears to be detrimental over time for spouses married to partners who frequently behaved negatively (McNulty, 2008). Intervention and experimental studies have also revealed that forgiving an offence enhances subjective well-being and reduces psychological distress (e.g., Coyle \& Enright, 1997; Karremans et al., 2003; Reed \& Enright, 2006). Similarly, one can argue that receiving forgiveness from a close other decreases a transgressor's distress and promotes his/her well-being by reducing uncertainty concerning the future of the relationship. In light of these observations, Study 2 tested the predictive validity of the
MOFS over a 6-month period by readministering to Study 1 participants some of the relationship and well-being measures previously used. We expected forgiveness would predict higher relationship quality, closeness, and life satisfaction and lower distress over time.

Furthermore, given that evidence for the discriminant validity of the MOFS was not completely satisfactory with reference to marital quality in Study 1, Study 2 examined it again by following the same procedure used previously.

\section{Method}

\section{Participants and Procedure}

Of the Study 1 participants, 118 married couples (mean years of marriage $=19.97, S D=6.93$ ) volunteered to participate in a second wave of data collection (T2), which took place 6 months after the first one. These couples did not differ from the couples who participated only in Study 1 with respect to any of the variables investigated. Questionnaires were readministered by following the same procedure used in Study 1.

\section{Measures}

As in Study 1, participants were asked to remember the most serious offence by their spouse during the last 6 months and to 
Table 2

Correlations of the MOFS Dimensions With Offence-Specific Affective-Cognitive Processes, Offence Severity, Relationship Variables, and Indicators of Well-Being (Study 1)

\begin{tabular}{|c|c|c|c|c|}
\hline \multirow[b]{2}{*}{ Variable } & \multicolumn{2}{|c|}{ Resentment-Avoidance } & \multicolumn{2}{|c|}{ Benevolence } \\
\hline & Husbands & Wives & Husbands & Wives \\
\hline \multicolumn{5}{|c|}{ Affective-cognitive reactions to the offence ${ }^{a}$} \\
\hline Affective empathy & $-.44^{* * * *}$ & $-.36^{* * * *}$ & $.63^{\text {***** }}$ & $.40^{* * * *}$ \\
\hline Rumination & $.62^{* * * *}$ & $.55^{* * * *}$ & $-.37^{* * * *}$ & $-.44^{* * * *}$ \\
\hline Responsibility attributions & $.49^{* * * *}$ & $.48^{* * *}$ & $-.26^{* *}$ & $-.39^{\text {***** }}$ \\
\hline \multicolumn{5}{|l|}{ Offence severity } \\
\hline Offence hurtfulness & $.29^{* * *}$ & $.30^{* * * *}$ & $-.28^{* *}$ & $-.20^{*}$ \\
\hline Offence seriousness & $.31^{* * * *}$ & $.37^{* * *}$ & $-.33^{* * * *}$ & $-.28^{* *}$ \\
\hline \multicolumn{5}{|l|}{ Relationship variables } \\
\hline Marital quality (self-report) $^{\mathrm{a}}$ & $-.42^{* * * *}$ & $-.61^{* * *}$ & $.51^{* * * *}$ & $.57^{* * *}$ \\
\hline Marital quality (other-report) & $-.38^{* * * *}$ & $-.28^{* *}$ & $.31^{* * * *}$ & $.27^{* *}$ \\
\hline Closeness (self-report) & $-.29^{* * * *}$ & -.16 & $.28^{* *}$ & $.42^{* * * *}$ \\
\hline Closeness (other-report) & $-.28^{* *}$ & -.13 & $.26^{* *}$ & $.22^{* *}$ \\
\hline Marital support (self-report) & $-.36^{* * * *}$ & $-.53^{* * *}$ & $.44^{* * * * * *}$ & $.49^{* * * * *}$ \\
\hline Marital support (other-report) & $-.28^{* *}$ & $-.26^{* *}$ & $.28^{* *}$ & $.24^{* *}$ \\
\hline \multicolumn{5}{|c|}{ Indicators of psychological well-being } \\
\hline Depression & $.33^{* * * *}$ & $.35^{* * * *}$ & $-.29^{* * * *}$ & $-.24^{* *}$ \\
\hline Self-esteem & $-.25^{* *}$ & $-.33^{* * * *}$ & $.21^{*}$ & $.28^{* *}$ \\
\hline Stress & $.34^{* * * *}$ & $.28^{* *}$ & $-.18^{*}$ & -.08 \\
\hline Satisfaction with life & $-.35^{* * *}$ & $-.38^{* * * *}$ & $.38^{* * * *}$ & $.32^{\text {***** }}$ \\
\hline
\end{tabular}

Note. $\quad N=148$

${ }^{a}$ Correlations between latent variables as estimated with maximum likelihood structural equation models.

${ }^{*} p<.05$. $^{* *} p<.01$. $^{* * * *} p<.001$.

assess the degree to which they had forgiven it through the final 10 -item version of the MOFS. The coefficient alpha was adequate for both MOFS dimensions (Resentment-Avoidance: $\alpha=.89$ for husbands and .83 for wives; Benevolence: $\alpha=.75$ for husbands and .84 for wives). On average, husbands and wives remembered moderately hurtful and serious offences, hurtfulness: $M=3.82$ $(S D=1.32)$ and $4.18(S D=1.55)$ for husbands and wives, respectively; seriousness: $M=3.50(S D=1.35)$ and $3.68(S D=$ 1.60) for husbands and wives, respectively. These values are comparable to those reported in Study 1. A general linear model analysis with gender and study (1 or 2) as repeated measures yielded no significant main effect of time for either hurtfulness, $F(1,107)=1.08, p=.30$, or seriousness, $F(1,107)=0.38$, $p=.54$.

Participants also evaluated their relationship quality, closeness, satisfaction with life, and stress by completing the QMI (Norton, 1983), the IOS Scale (Aron et al., 1992), the SWLS (Diener et al., 1985), and the WYSI (Canadian Mental Health Association, n.d.) The QMI, the SWLS, and the WYSI showed adequate internal consistency (for husbands and wives, respectively, QMI: $\alpha=.94$ and .96; SWLS: $\alpha=.87$ and .89; WYSI: $\alpha=.71$ and .78),

\section{Results and Discussion}

CFAs provided evidence for discriminant validity with regard to marital quality. Specifically, the one-factor solution combining the Resentment-Avoidance or the Benevolence items with the QMI items did not adequately fit the data for either husbands, Resentment-Avoidance: $\mathrm{Y}-\mathrm{B} \chi^{2}(53)=255.71, p=.00, \mathrm{R}-\mathrm{CFI}=.77$, $\mathrm{R}-\mathrm{RMSEA}=.18(90 \% \mathrm{CI}=0.16-0.20)$; Benevolence: $\mathrm{Y}-\mathrm{B} \chi^{2}(34)=77.49, p=.00, \mathrm{R}-\mathrm{CFI}=.94, \mathrm{R}-\mathrm{RMSEA}=.10$
(90\% CI $=0.07-0.13)$, or wives, Resentment-Avoidance: $\mathrm{Y}-\mathrm{B} \chi^{2}(53)=147.59, p=.00, \mathrm{R}-\mathrm{CFI}=.91, \mathrm{R}-\mathrm{RMSEA}=.12(90 \%$ $\mathrm{CI}=0.10-0.15)$; Benevolence: $\mathrm{Y}-\mathrm{B} \chi^{2}(34)=173.73, p=.00$, $\mathrm{R}-\mathrm{CFI}=.88, \mathrm{R}-\mathrm{RMSEA}=.19(90 \% \mathrm{CI}=0.16-0.21)$. In contrast, the two-factor solution with the Resentment-Avoidance or Benevolence items and the marital quality items loading on two separated factors showed a satisfactory fit: Husbands' Resentment-Avoidance: $\mathrm{Y}-\mathrm{B} \chi^{2}(52)=60.21, p=.20, \mathrm{R}-\mathrm{CFI}=1.00, \mathrm{R}-\mathrm{RMSEA}=.04(90 \%$ $\mathrm{CI}=0.00-0.07)$; Husbands' Benevolence: $\mathrm{Y}-\mathrm{B} \chi^{2}(33)=36.51, p=$ $.31, \mathrm{R}-\mathrm{CFI}=1.00, \mathrm{R}-\mathrm{RMSEA}=.03(90 \% \mathrm{CI}=0.00-0.08)$; Wives' Resentment-Avoidance: $\mathrm{Y}-\mathrm{B} \chi^{2}(52)=81.49, p=.01$, $\mathrm{R}-\mathrm{CFI}=.97, \mathrm{R}-\mathrm{RMSEA}=.07(90 \% \mathrm{CI}=0.04-0.10)$; Wives' Benevolence: $\mathrm{Y}-\mathrm{B} \chi^{2}(33)=57.39, p=.01, \mathrm{R}-\mathrm{CFI}=.98$, $\mathrm{R}-\mathrm{RMSEA}=.08(90 \% \mathrm{CI}=0.04-0.10)$. These results demonstrate that the introduction of a second factor led to a significant improvement in the model fit (the chi-square difference test was always significant at $p<.001)$.

To test the 6-month predictive validity of the MOFS, we used the Actor-Partner Interdependence Model (APIM) proposed by Kenny (1996). This data-analytic approach takes into account the interdependence between spouses by allowing the simultaneous estimation of the effect that a respondent's predictor has on his/her own outcome score (actor effect) and the effect of the partner's predictor on the respondent's outcome score (partner effect). In the present case, the path from a spouse's forgiveness dimension (Resentment-Avoidance or Benevolence) at Time 1 (T1) to his/her own rating of the relationship at Time 2 (T2) is the actor path, and the path from a spouse's forgiveness dimension at T1 to his/her partner's rating of the relationship at $\mathrm{T} 2$ is the partner path (see Figure 1). 


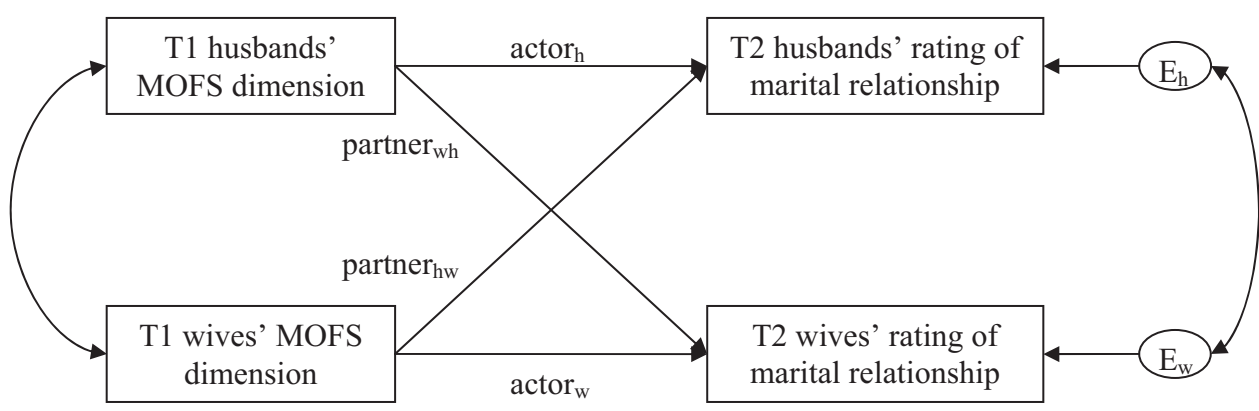

Figure 1. Actor-Partner Interdependence Model for Study 2. T1 = Time 1; T2 = Time 2; MOFS = Marital Offence-Specific Forgiveness Scale; $\mathrm{h}=$ husband; $\mathrm{w}=$ wife; $\mathrm{E}=$ error.

Eight APIMs, in which the two MOFS dimensions at T1 were alternatively entered as predictors and the two relationship and well-being measures at T2 were alternatively entered as outcomes, were tested via SEM (e.g., Kenny \& Acitelli, 2001). A powerful feature of SEM is that it allows one to compare and statistically evaluate whether actor and partner effects are different across husbands and wives. In order to test this difference we constrained the two actor and the two partner parameters to be equal and then assessed the degree to which constraints worsened the fit of the model via the chi-square difference test. The only significant difference to emerge was for Benevolence in that it was a stronger predictor of own marital quality for wives $(B=0.50)$ than for husbands $(B=0.34), \chi^{2}(1)=4.01, p=.04$. This finding is in line with some studies suggesting that the positive effects of forgiveness on self-rated marital quality are stronger for wives than for husbands because women are more relationship-oriented and less likely to adopt a "dismissive" style in response to relationship difficulties (e.g., Fincham \& Beach, 2007, p. 266).

In all the remaining cases there was no significant change in model fit, $\chi^{2}(1)<3.66$, and hence we report results for the more parsimonious constrained model. Actor and partner coefficients ${ }^{3}$ as well as the relative chi-square difference tests are reported in Table 3.

APIM coefficients indicate that both MOFS dimensions significantly predicted self-reported and other-reported T2 outcome variables, in both husbands and wives. That is, T1 ResentmentAvoidance predicted in the expected direction T2 self-reported satisfaction with life $(b=-.64)$ and, respectively, both selfreported and other-reported marital quality $(B \mathrm{~s}=-0.28$ and $-0.19)$, closeness $(B \mathrm{~s}=-0.15$ and -0.16$)$, and stress $(B \mathrm{~s}=0.32$ and 0.11); T1 Benevolence predicted T2 other-reported stress $(B=$ $-0.20)$ and, respectively, both self-reported and other-reported marital quality $(B \mathrm{~s}=0.34 / 0.50$ for husbands/wives and 0.22 ), closeness $(B \mathrm{~s}=0.29$ and 0.15$)$, and satisfaction with life $(B \mathrm{~s}=$ 0.26 and 0.12 ).

When controlling for validation scale scores at $\mathrm{T} 1$, we found that by entering them as further predictors in the APIM models, a number of coefficients remained significant (see results shown in parentheses in Table 3). Specifically, for both spouses Benevolence positively predicted self-reported marital quality $(b=.15)$ and negatively predicted other-reported stress $(b=-.08)$, while Resentment-Avoidance positively predicted self-reported stress $(b=.15)$. The finding that some APIM effects were still signifi- cant even when partialing out the T1 level of validation variables is especially noteworthy given the mismatch in level of specificity with which forgiveness and validation variables were assessed, which likely underestimates the longitudinal relationship between them. In other words, while the general tendency to forgive one's own partner across different offences (dyadic forgiveness) could be reasonably expected to predict global assessments of relational and personal well-being over a 6-month period, it is remarkable that forgiveness for a specific offence also predicted them. Most notably, the finding cannot be considered an artifact of the associations existing between relational and personal well-being (average $r=|.30|$ and $|.37|$ for husbands and wives, respectively) since the same APIM effects remained significant when controlling for both types of validation variables at T1 (for example, controlling for T1 marital quality as well as for T1 stress and satisfaction with life when predicting $\mathrm{T} 2$ marital quality).

\section{Study 3}

The previous two studies yielded evidence that the MOFS has satisfactory psychometric properties when used to assess marital offences in long-term marriages. The present study extended this evidence by cross-validating the measurement model for the MOFS and confirming its discriminant and convergent validity in a sample of short- to medium-term marriages. Offences occurring in earlier stages of a relationship may have different implications for the victim and induce different reactions in him/her than do offences taking place in the later stages of long-term relationships. This may happen because persons in the early stages of a relationship are more likely to have overly optimistic assumptions about the partner and the relationship, which serve to magnify the transgression. Alternatively, spouses in short- and medium-term marriages may actually experience more serious and hurtful offences that might potentially lead to marital dissolution. It is therefore important to assess whether the MOFS has satisfactory psychometric properties in such samples.

The discriminant validity of the MOFS was tested by verifying that marital forgiveness was empirically distinct from marital

\footnotetext{
${ }^{3}$ Before estimating models, we standardized the variables with means and standard deviations computed across husbands and wives so as to have coefficients comparable across dyad member type (see Kenny, Kashy, \& Cook, 2006).
} 
Table 3

APIM Coefficients and Chi-Square Difference Tests Comparing Actor and Partner Effects Across Spouses (Study 2)

\begin{tabular}{|c|c|c|c|c|}
\hline \multirow[b]{2}{*}{ Variable } & \multicolumn{2}{|l|}{ Actor effects } & \multicolumn{2}{|c|}{ Partner effects } \\
\hline & $B$ & $\begin{array}{c}\chi^{2} \text { difference } \\
\text { test }\end{array}$ & $B$ & $\begin{array}{c}\chi^{2} \text { difference } \\
\text { test }\end{array}$ \\
\hline $\mathrm{T} 1$ Resentment-Avoidance predicting $\mathrm{T} 2$ marital quality & $-0.28^{* * *}(-0.06)$ & $2.40(0.58)$ & $-0.19^{* *}(-0.04)$ & $0.45(0.93)$ \\
\hline $\mathrm{T} 1$ Benevolence predicting $\mathrm{T} 2$ marital quality & $\mathrm{H}=0.34^{* * * *}, \mathrm{~W}=0.50^{* * * * *}\left(0.15^{* *}\right)$ & $4.01^{*}(0.32)$ & $0.22^{\text {**** }}(0.01)$ & $1.01(0.77)$ \\
\hline T1 Resentment-Avoidance predicting T2 closeness & $-0.15^{* *}(-0.05)$ & $0.02(0.50)$ & $-0.16^{* *}(-0.07)$ & $0.01(3.14)$ \\
\hline T1 Benevolence predicting T2 closeness & $0.29^{* * * *}(0.09)$ & $2.32(0.12)$ & $0.15^{* *}(0.03)$ & $0.01(0.45)$ \\
\hline T1 Resentment-Avoidance predicting T2 stress & $0.32^{* * * * *}\left(0.15^{\text {*** }}\right)$ & $0.74(3.17)$ & $0.11^{*}(0.00)$ & $0.37(1.21)$ \\
\hline $\mathrm{T} 1$ Benevolence predicting $\mathrm{T} 2$ stress & $-0.08(0.00)$ & $0.18(0.33)$ & $-0.20^{* * *}\left(-0.08^{*}\right)$ & $0.31(0.14)$ \\
\hline T1 Resentment-Avoidance predicting T2 satisfaction with life & $-0.64^{* * *}(-0.07)$ & $0.79(2.38)$ & $-0.19(0.07)$ & $2.03(3.65)$ \\
\hline T1 Benevolence predicting T2 satisfaction with life & $0.26^{* * * *}(0.04)$ & $0.32(0.12)$ & $0.12^{*}(-0.03)$ & $0.56(2.17)$ \\
\hline
\end{tabular}

Note. $N=118$. APIM coefficients and chi-square difference tests shown in parentheses are calculated by partialing out T1 level of validation scales. $d f=$ 1 for all chi-square difference tests. APIM = Actor-Partner Interdependence Model; T1 = Time 1; T2 = Time 2; $\mathrm{H}=$ husbands; $\mathrm{W}=$ wives.

${ }^{*} p<.05 .^{* *} p<.01 .^{* * * *} p<.001$.

quality. Convergent validity was tested by analyzing the correlations of forgiveness dimensions with relationship variables (marital quality, closeness, effective conflict resolution, trusting the partner) as well as with trait forgiveness. Recent research has suggested that, besides marital quality and closeness, trusting the partner and perceiving the resolution of couple conflicts as effective are concurrently and positively associated with forgiving the partner (Fincham et al., 2004; Finkel, Burnette, \& Scissors, 2007). Therefore we expected that more benevolent and less avoidant and resentful spouses would report more effective arguing and more reciprocal trusting than would less forgiving spouses. We also predicted that, consistent with existing research showing modest association between offence-specific and trait forgiveness, the MOFS dimensions would be modestly correlated with trait forgiveness. Finally, forgiveness is generally viewed as a positive behavior in Western cultures, and as a result, self-report measures of forgiveness are susceptible to impression management, or socially desirable responding. The present study therefore included a measure of socially desirable responding so that it could be statistically controlled when examining the association between the MOFS and hypothesized correlates.

\section{Method}

\section{Participants and Procedure}

Participants were 180 couples married an average of 4.69 years $(S D=3.27)$ and living in Northern Italy. Husbands' mean age was 32.66 years $(S D=5.86)$, and wives' was 30.27 years $(S D=5.34)$.

Participants were recruited by inviting students in undergraduate courses to ask married friends to participate in a study on marital relationships. As in Study 1, couples who volunteered to participate received two packets, one for the husband and one for the wife, containing a questionnaire, return envelopes, and a cover letter instructing them on their task. The importance of independent completion of the materials was emphasized in the letter, and the couple was asked to mail the questionnaires within 1 week and to refrain from talking about the study until after they had mailed the materials.

\section{Measures}

Couples participating in the study were randomly divided into two subsamples. The first subsample $(n=89)$ was asked to think of the most serious offence by their spouse during the last 6 months, while the second subsample $(n=91)$ was asked to recall the most serious offence ever perpetrated by the partner. These different instructions were given in order to validate the MOFS in relation to offences having different temporal boundaries as well as different degrees of seriousness.

Participants rated offense seriousness and how hurtful it was to them, respectively, with 7-point Likert scales ranging from 1 (not serious at all) to 7 (very serious) and 1 (not hurtful at all) to 7 (very hurtful).

As expected, offences recalled by the second subsample were more temporally distant $(M=11.77$ months, $S D=0.81)$ than those reported by the first subsample ( $M=2.40$ months, $S D=$ $1.17)$ as well as those reported by Study 1 participants $(M=2.47$ months, $S D=0.60), F(2,287)=45.90, p=.00$. However, contrary to expectations, offences remembered by Study 3 subsamples did not differ significantly from each other or from those in the Study 1 sample in relation to both offence hurtfulness, $F(2$, $321)=0.43, n s$, and seriousness, $F(2,321)=1.08, n s$. The one exception was wives' perceived hurtfulness, which was greater in Study 3 subsamples $(M=4.78, S D=0.18 ; M=4.76, S D=0.18)$ than in the Study 1 sample $(M=4.34, S D=0.14), F(2,321)=$ $3.72, p=.02$.

Marital quality and closeness. As in Studies 1 and 2, marital quality and closeness were assessed with the QMI ( $\alpha \mathrm{s}=.95$ for husbands and .96 for wives) and the IOS.

Effective conflict resolution. We assessed effective conflict resolution with the Ineffective Arguing Inventory (Kurdek, 1994) by scoring it so that high scores reflected effective resolution. Developed on the basis of descriptions of ineffective arguing found in marital research, the inventory consists of eight items measuring each partner's view of how the respondent and his/her partner as a couple handle arguments (e.g., "Our arguments are left hanging and unresolved"). For each item, spouses rated their agreement with the statement on a 5-point scale ranging from 1 
(strongly disagree) to 5 (strongly agree). The internal consistency for this scale was high ( $\alpha \mathrm{s}=.83$ for husbands and .78 for wives).

Trust in the partner. Trust in the partner was measured with the 17-item Trust Scale (Rempel, Holmes, \& Zanna, 1985), which has three subscales: Faith (e.g., "When I am with my partner, I feel secure in facing unknown new situations"), Dependability (e.g., "I can rely on my partner to keep the promises he/she makes to me"), and Predictability (e.g., "My partner behaves in a very consistent manner"). Participants responded on a 7-point scale ranging from 1 (strongly disagree) to 7 (strongly agree). The three subscales were combined into a single measure of trust $(\alpha s=.84$ for husbands and .87 for wives).

Dispositional forgiveness. The tendency to forgive was measured with the Trait Forgivingness Scale (Berry \& Worthington, 2001). The scale consists of 10 items designed to assess a respondent's tendency to forgive interpersonal transgressions (e.g., "I can forgive a friend for almost anything"). Spouses were instructed to rate their degree of agreement with each of the 10 items on a 5-point Likert-type scale ranging from 1 (very strong disagreement) to 5 (very strong agreement). Coefficient alphas for the items, which loaded on a single factor, were .70 for husbands and .73 for wives.

Social desirability. The Marlowe-Crowne Social Desirability Scale (MCSD) was used to assess social desirability (Crowne \& Marlowe, 1960). Two items on this 33-item scale were omitted because of overlap with MOFS items. The instrument uses a true-false response format; consequently, the Kuder-Richardson formula (K-R 20) was used to compute internal consistency reliability. Coefficient alpha was .75 for husbands and .64 for wives.

\section{Results and Discussion}

\section{Dimensionality: Structural Equation Models}

Following the same procedure used in Study 1, we assessed the validity of the two-factor solution for the MOFS items by comparing it with a one-factor and with a three-factor solution. Given that two subsamples of spouses reported offences having different time boundaries and hurtfulness, the factorial invariance of the measurement models was tested across them through multigroup modeling. In testing for equivalences across subsamples, we constrained factor-loading paths and covariances to be equal.

The two-factor solution provided a good fit to the data for husbands, $\mathrm{S}-\mathrm{B} \chi^{2}(77)=84.62, p=.26, \mathrm{R}-\mathrm{CFI}=.98, \mathrm{R}-\mathrm{RMSEA}=.02$ $(90 \% \mathrm{CI}=0.00-0.05)$, and an acceptable one for wives, $\mathrm{S}-\mathrm{B} \chi^{2}(77)=106.12, p=.02, \mathrm{R}-\mathrm{CFI}=.93, \mathrm{R}-\mathrm{RMSEA}=.05(90 \%$ $\mathrm{CI}=0.02-0.07)$. The two factors were correlated at $r \mathrm{~s}=-.39$ and -.70 for husbands and wives, respectively.

Compared with the two-factor solution, the one-factor solution, in which the association between Resentment-Avoidance and Benevolence dimensions was constrained to unity, provided a poorer fit to the data: husbands: $\mathrm{S}-\mathrm{B} \chi^{2}(78)=191.22, p=.00, \mathrm{R}-\mathrm{CFI}=$ .75 , R-RMSEA $=.09(90 \% \mathrm{CI}=0.07-0.11), \Delta \chi^{2}(1)=106.06$, $p<.001$; wives: $\mathrm{S}-\mathrm{B} \chi^{2}(78)=159.94, p=.00, \mathrm{R}-\mathrm{CFI}=.80$, $\mathrm{R}-\mathrm{RMSEA}=.08(90 \% \mathrm{CI}=0.06-0.09), \Delta \chi^{2}(1)=53.82, p<$ .001 . Accordingly, the two-factor solution is preferable to a singlefactor solution.

The three-factor solution provided a satisfactory fit to the data: husbands: $\mathrm{S}-\mathrm{B} \chi^{2}(75)=80.51, p=.31$, R-CFI $=.99$,
R-RMSEA $=.02(90 \% \mathrm{CI}=0.00-0.05)$; wives: $\mathrm{S}-\mathrm{B} \chi^{2}(75)=$ $102.96, p=.02, \mathrm{R}-\mathrm{CFI}=.93$, R-RMSEA $=.05(90 \% \mathrm{CI}=$ 0.02-0.07). However, when the association between Resentment and Avoidance dimensions was constrained to unity, there was an equally good fit to the data: husbands: $\mathrm{S}-\mathrm{B} \chi^{2}(76)=83.30, p=$ $.27, \mathrm{R}-\mathrm{CFI}=.98, \mathrm{R}-\mathrm{RMSEA}=.02(90 \% \mathrm{CI}=0.00-0.05)$, $\Delta \chi^{2}(1)=2.79, p=n s$; wives: $\mathrm{S}-\mathrm{B} \chi^{2}(76)=106.25, p=.01$, $\mathrm{R}-\mathrm{CFI}=.93, \mathrm{R}-\mathrm{RMSEA}=.05(90 \% \mathrm{CI}=0.02-0.07), \Delta \chi^{2}(1)=$ $3.29, p=n s$. Thus, because of its parsimony, the two-factor solution is preferable to the three-factor one.

Finally, the congruence of the two-factor solution across gender was examined by estimating husbands' and wives' factor solutions simultaneously in a single-group model. In the model, corresponding factor loadings were constrained to be equal across the two genders, and latent factors and errors across the same indicators were allowed to correlate across husbands and wives. The model fit was acceptable, $\mathrm{S}-\mathrm{B} \chi^{2}(160)=231.65, p=.00, \mathrm{R}-\mathrm{CFI}=.93$, $\mathrm{R}-\mathrm{RMSEA}=.05(90 \% \mathrm{CI}=0.04-0.06)$, indicating that the Resentment-Avoidance and Benevolence dimensions have similar meanings for husbands and wives.

Internal consistency reliability was good for both the Resentment-Avoidance dimension $(\alpha \mathrm{s}=.79$ and .83 for husbands and wives, respectively) and the Benevolence dimension $(\alpha=.80$ and .76 for husbands and wives, respectively).

\section{Discriminant Validity}

To provide evidence of the discriminant validity of the MOFS, we distinguished each of its dimensions (i.e., ResentmentAvoidance and Benevolence) from the marital quality measure, following the same strategy used in Studies 1 and 2. The twofactor solutions, in which the items on one MOFS dimension and on the QMI loaded on two distinct but correlated latent factors, were superior to the corresponding one-factor solutions, in both husbands-Resentment-Avoidance: two-factor solution: $\mathrm{S}-\mathrm{B} \chi^{2}(52)=84.42, p=.00, \mathrm{R}-\mathrm{CFI}=.95, \mathrm{R}-\mathrm{RMSEA}=.06$ (90\% CI = 0.03-0.08); one-factor solution: $\mathrm{S}-\mathrm{B} \chi^{2}(53)=155.54$, $p=.00, \mathrm{R}-\mathrm{CFI}=.85, \mathrm{R}-\mathrm{RMSEA}=.10(90 \% \mathrm{CI}=0.09-0.12)$, $\Delta \chi^{2}(1)=71.12, p<.001$; Benevolence: two-factor solution: $\mathrm{S}-\mathrm{B} \chi^{2}(33)=71.21, p=.00, \mathrm{R}-\mathrm{CFI}=.94, \mathrm{R}-\mathrm{RMSEA}=.08$ $(90 \% \mathrm{CI}=0.05-0.10)$; one-factor solution: $\mathrm{S}-\mathrm{B} \chi^{2}(34)=175.94$, $p=.00, \mathrm{R}-\mathrm{CFI}=.79, \mathrm{R}-\mathrm{RMSEA}=.15(90 \% \mathrm{CI}=0.13-0.18)$, $\Delta \chi^{2}(1)=104.73, p<.001$-and wives-Resentment-Avoidance: two-factor solution: $\mathrm{S}-\mathrm{B} \chi^{2}(52)=116.35, p=.00, \mathrm{R}-\mathrm{CFI}=.91$, $\mathrm{R}-\mathrm{RMSEA}=.08(90 \% \mathrm{CI}=0.06-0.10)$; one-factor solution: $\mathrm{S}-\mathrm{B} \chi^{2}(53)=171.02, p=.00, \mathrm{R}-\mathrm{CFI}=.81, \mathrm{R}-\mathrm{RMSEA}=.11$ $(90 \% \mathrm{CI}=0.09-0.13), \Delta \chi^{2}(1)=54.67, p<.001$; Benevolence: two-factor solution: $\mathrm{S}-\mathrm{B} \chi^{2}(33)=70.37, p=.00, \mathrm{R}-\mathrm{CFI}=.94$, R-RMSEA $=.08(90 \% \mathrm{CI}=0.05-0.10)$; one-factor solution: $\mathrm{S}-\mathrm{B} \chi^{2}(34)=156.20, p=.00, \mathrm{R}-\mathrm{CFI}=.79, \mathrm{R}-\mathrm{RMSEA}=.14$ $(90 \% \mathrm{CI}=0.12-0.16), \Delta \chi^{2}(1)=85.83, p<.001$. Thus, further evidence was provided that the construct assessed by each MOFS dimension is related to, but not equivalent to, marital quality.

\section{Convergent Validity}

Bivariate relations of the MOFS dimensions with relationship variables, trait variables, and social desirability appear in Table 4. 
Table 4

Correlations of the MOFS Dimensions With Relationship and Trait Variables and Social Desirability (Study 3)

\begin{tabular}{|c|c|c|c|c|}
\hline \multirow[b]{2}{*}{ Variable } & \multicolumn{2}{|c|}{ Resentment-Avoidance } & \multicolumn{2}{|c|}{ Benevolence } \\
\hline & Husbands & Wives & Husbands & Wives \\
\hline \multicolumn{5}{|l|}{ Relationship variables } \\
\hline Marital quality (self-report) ${ }^{\mathrm{a}, \mathrm{b}}$ & $-.64^{* * * *}$ & $-.73^{* * * * *}$ & $.45^{* * * *}$ & $.43^{\text {****** }}$ \\
\hline Marital quality (other-report) ${ }^{\mathrm{a}}$ & $-.38^{* * * *}$ & $-.47^{* * * *}$ & .04 & .08 \\
\hline Closeness (self-report) ${ }^{\mathrm{a}}$ & $-.30^{* * * *}$ & $-.50^{* * * *}$ & $.17^{*}$ & $.32^{\text {****** }}$ \\
\hline Closeness (other-report) ${ }^{\mathrm{a}}$ & $-.29^{* * * *}$ & $-.35^{\text {**** }}$ & .13 & $.21^{* * *}$ \\
\hline Effective conflict resolution (self-report) ${ }^{\mathrm{a}}$ & $-.61^{* * * *}$ & $-.56^{* * * *}$ & $.28^{* * *}$ & $.27^{\text {****** }}$ \\
\hline Effective conflict resolution (other-report) ${ }^{\mathrm{a}}$ & $-.48^{* * * *}$ & $-.49^{* * * *}$ & .08 & $.26^{* * *}$ \\
\hline Trust in the partner (self-report) ${ }^{\mathrm{c}}$ & $-.42^{* * * *}$ & $-.66^{* * * *}$ & $.43^{* * *}$ & $.35^{* * *}$ \\
\hline Trust in the partner (other-report) ${ }^{\mathrm{c}}$ & $-.30^{* * *}$ & $-.31^{* *}$ & $.24^{* * *}$ & .16 \\
\hline Trait forgiveness ${ }^{c}$ & -.15 & -.18 & .05 & $.27^{* * *}$ \\
\hline Social desirability $^{\mathrm{d}}$ & -.12 & -.01 & $.24^{*}$ & .12 \\
\hline
\end{tabular}

Relationship variables. Relations between ResentmentAvoidance and self-reported and other-reported relationship variables were all significant for both husbands and wives and ranged from moderate to very strong. The findings indicate that lower resentment and avoidance were associated with perceiving the marriage as close and satisfying, with greater effectiveness in conflict resolution and more trust in the partner. The correlations of Resentment-Avoidance with self-reported effective conflict resolution and with wives' trust were strong but did not invalidate the discriminant validity of the MOFS. ${ }^{4}$

Benevolence also covaried significantly with all self-reported and with some other-reported relationship variables. However, compared with Resentment-Avoidance, Benevolence was less strongly correlated to self-reported and other-reported relationship variables. A test for significant differences between dependent correlations (Cohen \& Cohen, 1983) indicated that all the differences were significant or marginally significant except for husbands' self-reported and other-reported trust in the partner. The present results contrast with the stronger associations found for long-term married couples in Study 1 and suggest that the link between Benevolence and the correlates investigated may be weaker in early stages of a relationship. Compared with long-term couples, shorter term couples have a shorter shared history in which to invest in the relationship. For this reason it seems reasonable to infer that their benevolent motivation toward the offending partner and their willingness to restore the relationship with him/her may be less strongly related to relationship features.

Trait forgiveness. Mirroring previous results, ResentmentAvoidance and Benevolence had weak to modest associations with trait forgiveness. Studies by Allemand et al. (2007) and Rye et al. (2001) found that correlations between trait and episodic forgiveness ranged from .12 to .30 . These findings suggest that offence-specific forgiveness cannot be conceptualized as simply a behavioral indicator of trait forgiveness. In other words, a person who is usually willing to forgive other people might not be able to do the same in relation to a particular partner's offence. Similarly, an individual who for- gives his/her partner for a specific offence is not necessarily a person disposed to doing the same for nonpartner offences.

In any event, the MOFS dimensions were less strongly related to trait forgiveness than to relationship variables. Consistent with previous research, this finding demonstrated that relational characteristics may be more important in understanding forgiveness of interpersonal transgressions in close relationships than a global disposition to forgive (Allemand et al., 2007; Hoyt et al., 2005).

Social desirability. The MOFS dimensions did not covary significantly with social desirability except in the case of husbands' Benevolence. The modest correlation between social desirability and husbands' Benevolence $(r=.24)$ is consistent with previous results obtained by Rye and colleagues (2001; Brose et al., 2005) and by McCullough and colleagues (1998) in which correlations between offence-specific forgiveness and social desirability were .17 and .34 , respectively. Accordingly, the MOFS does not seem to be particularly susceptible to impression management.

\footnotetext{
${ }^{4}$ A two-factor oblique solution, in which Resentment-Avoidance and Effective Conflict Resolution/Trust in the Partner loaded on two distinct correlated latent factors, yielded a better fit to the data than did a one-factor solution constraining correlations between factors to unity: husbands' Effective Conflict Resolution: two-factor solution: $\mathrm{S}-\mathrm{B} \chi^{2}(75)=132.26, p=.00, \mathrm{R}-\mathrm{CFI}=.90, \mathrm{R}-\mathrm{RMSEA}=.07(90 \%$ $\mathrm{CI}=0.05-0.08$ ); one-factor solution: $\mathrm{S}-\mathrm{B} \chi^{2}(76)=173.34, p=.00$, $\mathrm{R}$-CFI $=.82, \mathrm{R}$-RMSEA $=.09(90 \% \mathrm{CI}=0.07-0.10), \Delta \chi^{2}(1)=41.08$, $p<.001$; wives' Effective Conflict Resolution: two-factor solution: $\mathrm{S}-\mathrm{B} \chi^{2}(75)=132.65, p=.00, \mathrm{R}-\mathrm{CFI}=.90, \mathrm{R}$-RMSEA $=.07(90 \% \mathrm{CI}=$ $0.05-0.08)$; one-factor solution: $\mathrm{S}-\mathrm{B} \chi^{2}(76)=194.27, p=.00$, R-CFI $=$ $.77, \mathrm{R}-\mathrm{RMSEA}=.09(90 \% \mathrm{CI}=0.08-0.11), \Delta \chi^{2}(1)=61.62, p<.001$; wives' Trust in the Partner: two-factor solution: $\mathrm{S}-\mathrm{B} \chi^{2}(42)=40.42, p=$ .54 , R-CFI $=1.00$, R-RMSEA $=.00(90 \% \mathrm{CI}=0.00-0.08)$; one-factor solution: $\mathrm{S}-\mathrm{B} \chi^{2}(43)=74.02, p=.00, \mathrm{R}-\mathrm{CFI}=.74, \mathrm{R}-\mathrm{RMSEA}=.09$ $(90 \% \mathrm{CI}=0.05-0.12), \Delta \chi^{2}(1)=33.60, p<.001$.
} 


\section{General Discussion}

Although theorizing and research on marital forgiveness has grown appreciably in recent years, few efforts have been made to develop psychometrically sound measures of the construct in close relationships. Studies 1-3 address this shortcoming by describing the psychometric properties of the MOFS, a 10-item measure assessing forgiveness toward the partner for a specific offence in the marriage.

Across the three studies, the MOFS appeared to have good psychometric properties. In particular, items loaded on two distinct but correlated dimensions: Benevolence and ResentmentAvoidance. This two-factor structure indicates that the presence of benevolent and conciliatory motivation toward the offender cannot be inferred from the absence of resentful and avoidant motivation, and likewise, the lack of benevolence does not imply the existence of resentful and avoidant motivation toward the partner. Accordingly, the strength of the relations between forgiveness and its correlates may vary as a function of whether the Benevolence dimension or the Resentment-Avoidance dimension is considered. In Study 1, for example, we found that in long-term couples the victim's attributions and ruminative thoughts about the offence were more strongly related to Resentment-Avoidance than to Benevolence, whereas emotional empathy was more strongly associated with Benevolence than with Resentment-Avoidance. Moreover, Study 3 showed that, compared with Benevolence, Resentment-Avoidance is more strongly related with concurrent relationship variables in short- and medium-term marriages. Thus, consistent with recent theoretical and empirical literature (for reviews see Fincham, Hall, \& Beach, 2005, 2006), it can reasonably be argued that the absence of negative reactions toward the offender and the presence of positive reactions are both needed in order to fully assess marital forgiveness.

The two-factor structure also suggests that resentful and avoidant motivations tend to coexist in marital relationships. This finding, which is supported by previous theorizing and research (Fincham, Hall, \& Beach, 2005, 2006), indicates that married people are likely to either (a) experience both resentment toward and physical/psychological withdrawal from the offending partner, or else (b) choose estrangement from the partner as a way of expressing their resentment toward him/her.

Across the studies, the Benevolence and ResentmentAvoidance subscales, despite their brevity, had high internal consistency. They also correlated in theoretically expected ways with a variety of sociocognitive, relationship, trait, and well-being variables. In particular, we found evidence that both forgiveness dimensions are associated with sociocognitive reactions to the offence such as responsibility attributions, rumination, and affective empathy. In addition, Benevolence and ResentmentAvoidance covaried with a host of self-reported and partnerreported relationship variables, including marital quality, closeness, marital support, effective conflict resolution, and trust. Interestingly, Benevolence seems to be more strongly related to relationship variables in longer term rather than shorter term married couples, perhaps because of their stronger sense of "weness." Also, Benevolence and Resentment-Avoidance correlated moderately with trait forgiveness. Replicating previous research (Allemand et al., 2007), these correlations were weaker than the ones found with relationship variables. Finally, as expected (Kar- remans et al., 2003; Rye et al., 2001), forgiveness dimensions were associated with indicators of psychological well-being such as depression, self-esteem, stress, and satisfaction with life.

Some evidence of predictive validity for the forgiveness dimensions was also found. Study 2 showed that Benevolence accounted for variability in self-reported marital quality and partner-reported distress over a 6-month period, while Resentment-Avoidance explained some of the variability in self-reported distress. This finding, which is not an artifact of the association with validation scales, is especially noteworthy in light of the mismatch in level of specificity with which forgiveness and relationship variables were assessed, a mismatch that likely led to underestimation of the temporal relationship between them. It is particularly noteworthy that we were able to demonstrate that our results did not simply reflect sentiment override as forgiveness emerged in our analyses as separate from, but related to, marital quality and accounted for variance in the correlates investigated when marital quality was statistically controlled.

The above results seem to hold across offences having different temporal boundaries as well as across couples at different stages in the marital life cycle. Nonetheless, they should be viewed in the light of several limitations. Chief among these is the limited variability of the samples recruited, which restricts the generalizability of the findings. Study participants were all volunteers living in Northern Italy and tended to be in well-adjusted marital relationships. Future research should determine whether the MOFS performs adequately in different cultures, especially within English-speaking ones, as well as with more distressed marital samples. Volunteer or self-selection bias effects should also be examined. A second limitation lies in the reliance on self-report measures in the present studies. Although we validated the MOFS against ratings by the partner, future research should validate it against behavioral observations of forgiving behavior.

Notwithstanding the limitations outlined, the development of the MOFS represents an important step in the development of a marital forgiveness literature based on the use of theoretically informed, psychometrically sound measures. With the growth of interventions that attempt to facilitate forgiveness in intimate relationships, the need for psychometrically sound assessment devices is important. The MOFS is an attempt to fill this need.

\section{References}

Afifi, W., Falato, W., \& Weiner, J. (2001). Identity concerns following a severe relational transgression: The role of discovery method for relational outcomes of infidelity. Journal of Social and Personal Relationships, 18, 291-308.

Allemand, M., Amberg, I., Zimprich, D., \& Fincham, F. D. (2007). The role of trait forgiveness and relationship satisfaction in episodic forgiveness. Journal of Social and Clinical Psychology, 26, 199-217.

Aron, A., Aron, E. N., \& Smollan, D. (1992). Inclusion of Other in the Self Scale and the structure of interpersonal closeness. Journal of Personality and Social Psychology, 63, 596-612.

Bagozzi, R. P., Yi, Y., \& Phillips, L. W. (1991). Assessing construct validity in organizational research. Administrative Science Quarterly, $36,421-458$.

Bentler, P. M. (1990). Comparative fit indexes in structural models. Psychological Bulletin, 107, 238-246.

Bentler, P. M. (1995). EQS structural equations program manual. Encino, CA: Multivariate Software. 
Bentler, P. M. (2005). EQS 6 structural equations program manual. Encino, CA: Multivariate Software.

Bentler, P. M., \& Chou, C. P. (1987). Practical issues in structural modeling. Sociological Methods and Research, 16, 78-117.

Berry, J. W., \& Worthington, E. L., Jr. (2001). Forgivingness, relationship quality, stress while imagining relationship events, and physical and mental health. Journal of Counseling Psychology, 48, 447-455.

Bollen, K. A. (1980). Issues in the comparative measurement of political democracy. American Sociological Review, 45, 370-390.

Brose, L. A., Rye, M. S., Lutz-Zois, C., \& Ross, S. R. (2005). Forgiveness and personality traits. Personality and Individual Differences, 39, $35-46$.

Canadian Mental Health Association. (n.d.). What's your stress test index? Available at http://www.cmha-tb.on.ca/bins/content_page.asp?cid=4$42-216$

Cohen, J., \& Cohen, P. (1983). Applied multiple regression/correlation analysis for the behavioral sciences. Hillsdale, NJ: Erlbaum.

Coyle, C. T., \& Enright, R. D. (1997). Forgiveness intervention with postabortion men. Journal of Consulting and Clinical Psychology, 65, 1042-1046

Crowne, D. P., \& Marlowe, D. (1960). Social desirability independent of psychopathology. Journal of Consulting Psychology, 24, 349-354.

Diener, E., Emmons, R. A., Larsen, R. J., \& Griffin, S. (1985). The Satisfaction With Life Scale. Journal of Personality Assessment, 49, 71-75.

Eaton, J., Struthers, C. W., \& Santelli, A. G. (2006). Dispositional and state forgiveness: The role of self-esteem, need for structure, and narcissism. Personality and Individual Differences, 41, 371-380.

Enright, R. D., Freedman, S., \& Rique, J. (1998). The psychology of interpersonal forgiveness. In R. D. Enright \& J. North (Eds.), Exploring forgiveness (pp. 46-63). Madison: University of Wisconsin Press.

Exline, J. J., Baumeister, R. F., Bushman, B. J., Campbell, W. K., \& Finkel, E. J. (2004). Too proud to let go: Narcissistic entitlement as a barrier to forgiveness. Journal of Personality and Social Psychology, 87, 894912.

Fenell, D. L. (1993). Characteristics of long-term first marriages. Journal of Mental Health Counseling, 15, 446-460.

Fincham, F. D. (in press). Forgiveness: Integral to a science of close relationships? In Prosocial motives, emotions, and behavior: The better angels of our nature. Washington, DC: American Psychological Association.

Fincham, F. D., \& Beach, S. R. (2002). Forgiveness in marriage: Implications for psychological aggression and constructive communication. Personal Relationships, 9, 239-251.

Fincham, F. D., \& Beach, S. R. H. (2007). Forgiveness and marital quality: Precursor or consequence in well-established relationships. Journal of Positive Psychology, 2, 260-268.

Fincham, F. D., Beach, S. R., \& Davila, J. (2004). Forgiveness and conflict resolution in marriage. Journal of Family Psychology, 18, 72-81.

Fincham, F. D., Beach, S. R. H., \& Davila, J. (2007). Longitudinal relations between forgiveness and conflict resolution in marriage. Journal of Family Psychology, 21, 542-545.

Fincham, F. D., \& Bradbury, T. N. (1992). Assessing attributions in marriage: The Relationship Attribution Measure. Journal of Personality and Social Psychology, 62, 457-468.

Fincham, F. D., Garnier, P. C., Gano-Phillips, S., \& Osborne, L. N. (1995). Pre-interaction expectations, marital satisfaction, and accessibility: A new look at sentiment override. Journal of Family Psychology, 9, 3-14.

Fincham, F. D., Hall, J. H., \& Beach, S. R. H. (2005). Til lack of forgiveness doth us part: Forgiveness in marriage. In E. L. Worthington (Ed.), Handbook of forgiveness (pp. 207-226). New York: Routledge.

Fincham, F. D., Hall, J., \& Beach, S. R. H. (2006). Forgiveness in marriage: Current status and future directions. Family Relations, 55, 415-427.
Fincham, F. D., Jackson, H., \& Beach, S. R. H. (2005). Transgression severity and forgiveness: Different moderators for objective and subjective severity. Journal of Social and Clinical Psychology, 24, 860-875.

Fincham, F. D., Paleari, F. G., \& Regalia, C. (2002). Forgiveness in marriage: The roles of relationship quality, attributions and emotions. Personal Relationships, 9, 27-37.

Finkel, E. J., Burnette, J. L., \& Scissors, L. E. (2007). Vengefully ever after: Destiny beliefs, state attachment anxiety, and forgiveness. Journal of Personality and Social Psychology, 92, 871-886.

Gordon, K. C., \& Baucom, D. H. (2003). Forgiveness and marriage: Preliminary support for a measure based on a model of recovery from a marital betrayal. American Journal of Family Therapy, 31, 179-199.

Hall, J. H., \& Fincham, F. D. (2006). Relationship dissolution following infidelity: The roles of attributions and forgiveness. Journal of Social and Clinical Psychology, 25, 508-522.

Hambleton, R. K. (1994). Guidelines for adapting educational and psychological tests: A progress report. European Journal of Psychological Assessment, 10, 229-244.

Horowitz, M. J. (1985). Disasters and psychological responses to stress. Psychiatric Annals, 15, 161-167.

Horowitz, M. J., Wilner, N., \& Alvarez, W. (1979). Impact of Event Scale: A measure of subjective stress. Psychosomatic Medicine, 41, 209-218.

Hoyt, W. T., Fincham, F., McCullough, M. E., Maio, G., \& Davila, J. (2005). Responses to interpersonal transgressions in families: Forgivingness, forgivability, and relationship-specific effects. Journal of Personality and Social Psychology, 89, 375-394.

Jamshidian, M., \& Bentler, P. M. (1999). ML estimation of mean and covariance structures with missing data using complete data routines. Journal of Educational and Behavioral Statistics, 24, 21-41.

Karremans, J. C., Van Lange, P. A. M., Ouwerkerk, J. W., \& Kluwer, E. S. (2003). When forgiving enhances psychological well-being: The role of interpersonal commitment. Journal of Personality and Social Psychology, 84, 1011-1026.

Kenny, D. (1996). Models of nonindependence in dyadic research. Journal of Social and Personal Relationships, 13, 279-294.

Kenny, D. A., \& Acitelli, L. K. (2001). Accuracy and bias in the perception of the partner in a close relationship. Journal of Personality and Social Psychology, 80, 439-448.

Kenny, D. A., \& Kashy, D. A. (1992). Analysis of the multitraitmultimethod matrix by confirmatory factor analysis. Psychological Bulletin, 112, 165-172.

Kenny, D., Kashy, D., \& Cook, W. (2006). Dyadic data analysis. New York: Guilford Press.

Kline, R. B. (2005). Principles and practice of structural equation modeling: Methodology in the social sciences (2nd ed.). New York: Guilford Press.

Kurdek, L. (1994). Conflict resolution styles in gay, lesbian, heterosexual nonparent, and heterosexual parent couples. Journal of Marriage and the Family, 56, 705-722.

Lawler, K. A., Younger, J. W., Piferi, R. L., Jobe, R. L., Edmondson, K. A., \& Jones, W. H. (2005). The unique effects of forgiveness on health: An exploration of pathways. Journal of Behavioral Medicine, 28, $157-167$.

Mardia, K. V. (1970). Measures of multivariate skewness and kurtosis with applications. Biometrika, 57, 519-530.

McCullough, M. E. (2001). Forgiveness: Who does it and how do they do it? Current Directions in Psychological Science, 10, 194-197.

McCullough, M. E., Bono, G., \& Root, L. M. (2007). Rumination, emotion, and forgiveness: Three longitudinal studies. Journal of Personality and Social Psychology, 92, 490-505.

McCullough, M. E., \& Hoyt, W. T. (2002). Transgression-related motivational dispositions: Personality substrates of forgiveness and their links to the Big Five. Personality and Social Psychology Bulletin, 28, 15561573. 
McCullough, M. E., Hoyt, W. T., \& Rachal, K. C. (2000). What we know (and need to know) about assessing forgiveness constructs. In M. E. McCullough, K. I. Pargament, \& C. E. Thoresen (Eds.), Forgiveness: Theory, research, and practice (pp. 299-319). New York: Guilford Press.

McCullough, M. E., Rachal, K. C., Sandage, S. J., Worthington, E. L., Jr., Brown, S. W., \& Hight, T. L. (1998). Interpersonal forgiving in close relationships: II. Theoretical elaboration and measurement. Journal of Personality and Social Psychology, 75, 1586-1603.

McCullough, M. E., Root, L. M., \& Cohen, A. D. (2006). Writing about the benefits of an interpersonal transgression facilitates forgiveness. Journal of Consulting and Clinical Psychology, 74, 887-897.

McCullough, M. E., Worthington, E. L., \& Rachal, K. C. (1997). Interpersonal forgiving in close relationships. Journal of Personality and Social Psychology, 73, 321-336.

McDonald, R. P. (1985). Factor analysis and related methods. Hillsdale, NJ: Erlbaum.

McNulty, J. K. (2008). Forgiveness in marriage: Putting the benefits into context. Journal of Family Psychology, 22, 171-175.

Norton, R. (1983). Measuring marital quality: A critical look at the dependent variable. Journal of Marriage and the Family, 45, 141-151.

Orathinkal, J. A., \& Vansteenwegen, A. (2007). Religiosity and forgiveness among first-married and remarried adults. Mental Health, Religion and Culture, 10, 379-394.

Paleari, F. G., Regalia, C., \& Fincham, F. D. (2005). Marital quality, forgiveness, empathy, and rumination: A longitudinal analysis. Personality and Social Psychology Bulletin, 31, 368-378.

Paleari, F. G., Rosnati, R., \& Lanz, M. (2002). Il supporto nelle relazioni familiari e il benessere dei giovani adulti: Differenze di prospettiva [Support in family relations and young adults' well-being: Differences of perspectives]. Ricerche di Psicologia, 25(4), 39-56.

Radloff, L. F. (1977). The CES-D scale: A self-report depression scale for research in the general population. Applied Psychological Measurement, 1, 385-401.

Raykov, T., \& Marcoulides, G. A. (2000). A first course in structural equation modeling. Mahwah, NJ: Erlbaum.

Reed, G. L., \& Enright, R. D. (2006). The effects of forgiveness therapy on depression, anxiety, and posttraumatic stress for women after spousal emotional abuse. Journal of Consulting and Clinical Psychology, 74, 920-929.
Rempel, J. K., Holmes, J. G., \& Zanna, M. P. (1985). Trust in close relationships. Journal of Personality and Social Psychology, 49, 95-112.

Resick, P. A., \& Calhoun, K. S. (2001). Post-traumatic stress disorder. In D. H. Barlow (Ed.), Clinical handbook of psychological disorders (3rd ed., pp. 60-113). New York: Guilford Press.

Roberts, R. C. (1995). Forgivingness. American Philosophical Quarterly, 32, 289-306

Rosenberg, M. (1965). Society and the adolescent self-image. Princeton, NJ: Princeton University Press.

Russell, D. W. (2002). In search of underlying dimensions: The use (and abuse) of factor analysis. Personality and Social Psychology Bulletin, $28,1629-1646$

Rye, M. S., Loiacono, D. M., Folck, C. D., Olszewski, B. T., Heim, T. A., \& Madia, B. P. (2001). Evaluation of the psychometric properties of two forgiveness scales. Current Psychology, 20, 260-277.

Satorra, A., \& Bentler, P. M. (2001). A scaled difference chi-square test statistic for moment structure analysis. Psychometrika, 66, 507-514.

Subkoviak, M. J., Enright, R. D., Wu, C.-R., Gassin, E. A., Freedman, S., Olson, L. M., \& Sarinopoulos, I. (1995). Measuring interpersonal forgiveness in late adolescence and middle adulthood. Journal of Adolescence, 18, 641-655.

Tsang, J., McCullough, M., \& Fincham, F. D. (2006). Forgiveness and the psychological dimension of reconciliation: A longitudinal analysis. Journal of Social and Clinical Psychology, 25, 404-428.

Ullman, J. B. (2001). Structural equation modeling. In B. G. Tabachnick \& L. S. Fidell (Eds.), Using multivariate statistics (pp. 653-771). Needham Heights, MA: Allyn \& Bacon.

Williamson, I., \& Gonzales, M. H. (2007). The subjective experience of forgiveness: Positive construals of the forgiveness experience. Journal of Social and Clinical Psychology, 26, 407-446.

Worthington, E. L., Jr., \& Wade, N. G. (1999). The social psychology of unforgiveness and forgiveness and implications for clinical practice. Journal of Social and Clinical Psychology, 18, 385-418.

Wothke, W. (2000). Longitudinal and multi-group modeling with missing data. In T. B. Little, K. U. Schnabel, \& J. Baumert (Eds.), Modeling longitudinal and multilevel data: Practical issues, applied approaches, and specific examples (pp. 219-240). Mahwah, NJ: Erlbaum.

Yuan, K.-H., \& Bentler, P. M. (1998). Normal theory based test statistics in structural equation modeling. British Journal of Mathematical and Statistical Psychology, 51, 289-309. 


\section{Appendix}

\section{Marital Offence-Specific Forgiveness Scale}

Each of the following statements describes possible feelings, thoughts, and behaviors you might currently experience in re- sponse to the offence. Please indicate the extent to which you agree or disagree with each statement by using the rating scale below.

Table A1

\begin{tabular}{|c|c|c|c|c|c|c|c|c|c|}
\hline 1 & 2 & 3 & 4 & & \multicolumn{2}{|c|}{5} & & \multicolumn{2}{|l|}{6} \\
\hline $\begin{array}{l}\text { strongly } \\
\text { disagree }\end{array}$ & disagree & $\begin{array}{l}\text { somewhat } \\
\text { disagree }\end{array}$ & $\begin{array}{l}\text { somewhat } \\
\text { agree }\end{array}$ & & \multicolumn{2}{|c|}{ agree } & & \multicolumn{2}{|l|}{$\begin{array}{l}\text { strongly } \\
\text { agree }\end{array}$} \\
\hline \multicolumn{4}{|c|}{ 1. Since my wife/husband behaved that way, I have been less willing to talk to her/him. } & 1 & 2 & 3 & 4 & 5 & 6 \\
\hline \multicolumn{4}{|c|}{$\begin{array}{l}\text { 2. Although she/he hurt me, I definitely put what happened aside so that we could resume } \\
\text { our relationship. }\end{array}$} & 1 & 2 & 3 & 4 & 5 & 6 \\
\hline \multicolumn{4}{|c|}{ 3. Since my wife/husband behaved that way, I get annoyed with her/him more easily. } & 1 & 2 & 3 & 4 & 5 & 6 \\
\hline \multicolumn{4}{|c|}{ 4. I make my wife/husband feel guilty for what happened. } & 1 & 2 & 3 & 4 & 5 & 6 \\
\hline \multicolumn{4}{|c|}{$\begin{array}{l}\text { 5. Since my wife/husband behaved that way, I have done my best to restore my relationship } \\
\text { with her/him. }\end{array}$} & 1 & 2 & 3 & 4 & 5 & 6 \\
\hline \multicolumn{4}{|c|}{$\begin{array}{l}\text { 6. I would like to behave toward my wife/husband in the same way that she/he behaved } \\
\text { toward me. }\end{array}$} & 1 & 2 & 3 & 4 & 5 & 6 \\
\hline \multicolumn{4}{|c|}{ 7. Because of what happened, I find it difficult to be loving toward her/him. } & 1 & 2 & 3 & 4 & 5 & 6 \\
\hline \multicolumn{4}{|c|}{ 8. I still hold some grudge against my wife/husband because of what she/he did. } & 1 & 2 & 3 & 4 & 5 & 6 \\
\hline \multicolumn{4}{|c|}{ 9. I forgave her/him completely, thoroughly. } & 1 & 2 & 3 & 4 & 5 & 6 \\
\hline \multicolumn{4}{|c|}{ 10. I soon forgave her/him. } & 1 & 2 & 3 & 4 & 5 & 6 \\
\hline
\end{tabular}

Resentment-Avoidance items: 1, 3, 4, 6, 7, 8. Benevolence items: 2, 5, 9, 10.

Received January 15, 2008

Revision received March 6, 2009

Accepted March 17, 2009 